\title{
Hydrogel Nanosensors for Colorimetric Detection and Dosimetry in Proton Beam Radiotherapy
}

\author{
by
}

\section{Sahil Inamdar}

\section{A Thesis Presented in Partial Fulfilment of the requirements for the Degree \\ Master of Science}

Approved November 2017 by the Graduate Supervisory Committee:

Kaushal Rege, Chair

Aman Anand

Brent Nannenga

\section{ARIZONA STATE UNIVERSITY}

December 2017 


\begin{abstract}
Proton beam therapy (PBT) is a state-of-the-art radiotherapy treatment approach that uses focused proton beams for tumor ablation. A key advantage of this approach over conventional photon radiotherapy (XRT) is the unique dose deposition characteristics of protons, resulting in superior healthy tissue sparing. This results in fewer unwanted side effects and improved outcomes for patients. Current available dosimeters are intrinsic, complex and expensive; hence cannot be used to determine the dose delivered to the tumor routinely. Here, we report a hydrogel based plasmonic nanosensor for measurements of clinical doses in ranges between 2-4 Gy $\mathrm{RBE}$. In this nanosensor, gold ions, encapsulated in a hydrogel, are reduced to gold nanoparticles following irradiation with proton beams. Formation of gold nanoparticles renders a color change to the originally colorless hydrogel. The intensity of the color can be used to calibrate the hydrogel nanosensor in order to quantify different radiation doses employed during treatment. The potential of this nanosensor for clinical translation was demonstrated using an anthropomorphic phantom mimicking a clinical radiotherapy session. The simplicity of fabrication, detection range in the fractionated radiotherapy regime and ease of detection with translational potential makes this a first-in-kind plasmonic colorimetric nanosensor for applications in clinical proton beam therapy.
\end{abstract}

KEYWORDS: Protons, Gold nanoparticles, Hydrogel, Sensor, Colorimetric 
Dedicated to my Parents,

Hemant and Sangita Inamdar 


\section{ACKNOWLEDGMENTS}

I would like to start by thanking my advisor, Dr. Kaushal Rege for giving me this great opportunity to work on this exciting and upcoming field of radiation dosimetry for proton beam therapy. I am grateful for his support, guidance and inspiration and also his trust and belief in my abilities. His constant motivation and encouragement has definitely given me the push towards excellence. His deep involvement in the project was crucial in maintaining the pace at which I was working. I am truly blessed to have him has my mentor and guide, from whom I learnt the importance of hardwork and perseverance and also the value of discipline, punctuality and work ethic. I thank Dr. Rege for steering my career in the right direction.

I would like to thank Dr. Aman Anand at Mayo Clinic Phoenix - Arizona, for kindly agreeing to serve on my thesis committee. His expertise and knowledge in the field was of great help to the project. He also helped me in understanding the basic concepts of proton therapy and also instrumental throughout the project with his insights to understand the length and depth of the project.

I would also like to thank Dr. Brent Nannenga for agreeing to serve on my thesis committee. His help and inputs throughout the course of the project to put together my thesis was immense.

I would also like to thank Dr. Martin Bues and Jarrod Lentz from Mayo Clinic Phoenix Arizona, without whom this project wouldn't have been possible. They extended their full support to use the facility whenever we wanted and also made the treatment plan needed for the experiments. 
I would like to thank all the former and current members of Dr. Kaushal Rege's lab from whom I learnt a great deal. It was an absolute pleasure to work with such a talented group of people: Karthik Pushpavanam Subramaniam, Dr. Taraka Sai Pavan Grandhi, Dr. Matt Christensen, Dr. Sudhakar Godesha, Dr. Sheba Goklany, Russ Urie, Rajesh Niti, Deepanjan Ghosh, Maryam Ridha, Mellika Meraji, Kevin Lin, Andy Dobos and Harini Murali. I would like to take to this opportunity to thank Karthik Subramaniam Pushpavanam, a PhD student in Dr. Kaushal Rege's lab who was helped me throughout the project and without whom this study wouldn't have been possible.

I am very grateful to Ms. Bhoomika Sheth, Ms. Samruddhi Patil and Mr. Narayan Kanhere for their constant support throughout the course of my degree.

I would also like to thank National Science Foundation grant to have funded this project. I would like to thank Fred Pena for helping in fixing equipment issues in lab. Without his help a lot of valuable research time would have been lost. I also gratefully acknowledge the use of facilities at the LeRoy Eyring Center for Solid State Science at Arizona State University, Tempe, AZ.

Lastly, I am grateful to my parents for their constant support and encouragement throughout my life. Their belief in me has enabled me to pursue my dream. 


\section{TABLE OF CONTENTS}

Page

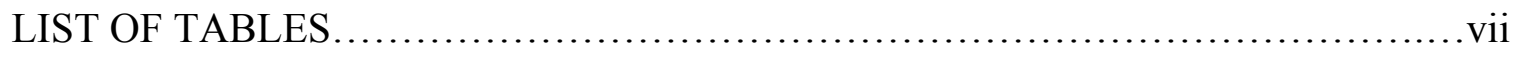

LIST OF FIGURES.........................................................................ii

\section{CHAPTER}

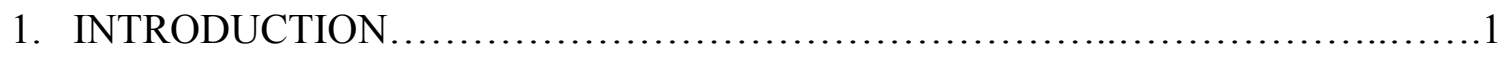

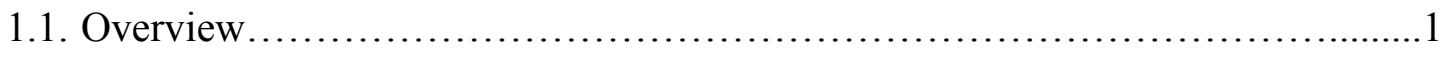

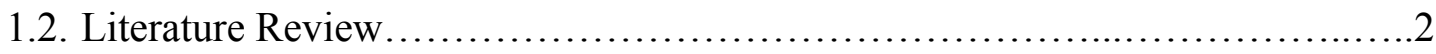

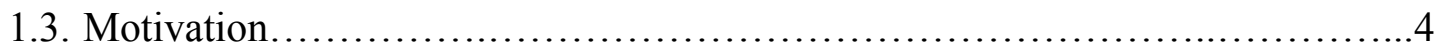

2. HYDROGEL NANOSENSOR FOR COLORIMETRIC DETECTION AND DOSIMETRY OF PROTON BEAMS............................................6

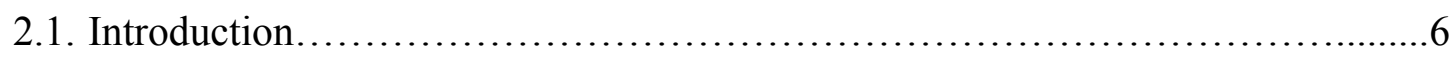

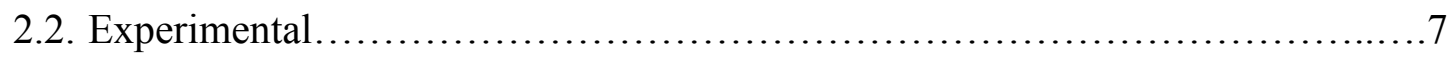

2.3. Result and Discussion....................................................11

3. CONCLUSION AND FUTURE WORK ........................................ 35

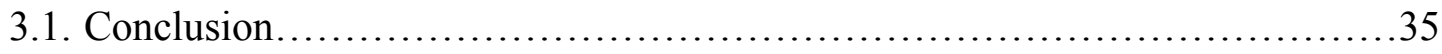

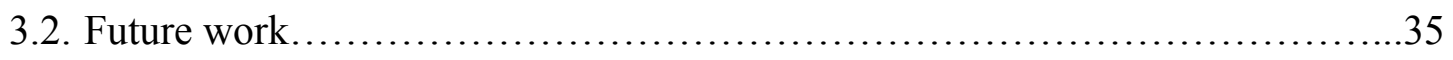

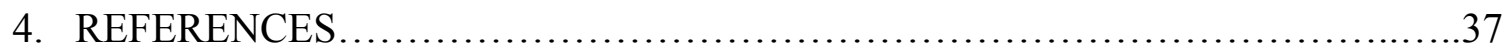




\section{LIST OF TABLES}

Table

Page

2.3.1. Actual and Experimental Dose Detection by Different Surfactants..............33 


\section{LIST OF FIGURES}

Figures

Page

2.3.1. Schematic of Hydrogel Nanosensor Dosimeters for Proton Beam Therapy.......11

2.3.2. Images of Controls of Agarose Gels Acquired 2 hrs post a 2 Gy

Dose without the Addition of Ascorbic Acid................................14

2.3.3. Image of Control of Agarose Gels Acquired 2 hrs post a 2 Gy $_{\mathrm{RBE}}$ Radiation Dose containing Only $\mathrm{HAuCl}_{4}$ without Ascorbic Acid and Surfactant.................14

2.3.4. Images of Hydrogel Nanosensors containing $C_{10} \mathrm{TAB}$ Irradiated with Different Doses of Proton Beams

2.3.5. Images of Hydrogel Nanosensors containing $\mathrm{C}_{12} \mathrm{TAB}, \mathrm{C}_{14} \mathrm{TAB}$ and $\mathrm{C}_{16} \mathrm{TAB}$ Surfactants with Different Proton Beams....................................16

2.3.6. Transmission Electron Microscopy (TEM) Micrographs of Gold Nanoparticles with $\mathrm{C}_{12} \mathrm{TAB}$ as Surfactant 18

2.3.7. Absorbance Spectra of Nanosensor Gels Containing $\mathrm{C}_{10} \mathrm{TAB}, \mathrm{C}_{12} \mathrm{TAB}, \mathrm{C}_{14} \mathrm{TAB}$ and $\mathrm{C}_{16} \mathrm{TAB}$ as Surfactants Post Irradiation with Proton Beams at Different Doses.

2.3.8. Kinetics of Gold Nanoparticles in Agarose Hydrogels with $\mathrm{C}_{10} \mathrm{TAB}, \mathrm{C}_{12} \mathrm{TAB}$, $\mathrm{C}_{14} \mathrm{TAB}$ and $\mathrm{C}_{16} \mathrm{TAB}$ with Protons

2.3.9. A Plot Depicting Maximum Absorbance vs Radiation Dose of the Nanosensor Gel containing $\mathrm{C}_{10} \mathrm{TAB}$ and $\mathrm{C}_{16} \mathrm{TAB}$ following Irradiation with Proton Beam Therapy 
Figures

2.3.10. A Plot Depicting Maximum Absorbance vs Radiation Dose of the Nanosensor Gel containing $\mathrm{C}_{12} \mathrm{TAB}$ and $\mathrm{C}_{14} \mathrm{TAB}$ following Irradiation with Proton Beam

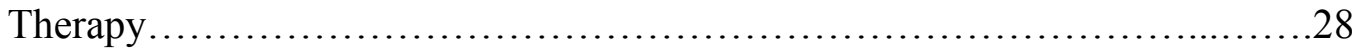

2.3.11. Calibration Curve for $\mathrm{C}_{12} \mathrm{TAB}$ and $\mathrm{C}_{14} \mathrm{TAB}$ using Maximum Absorbance vs

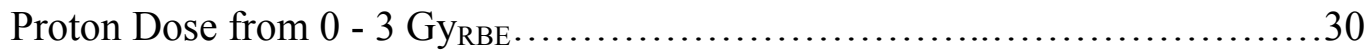

2.3.12. Evaluation of the Predictive Ability of Hydrogel Nanosensors using an Anthropomorphic Child Phantom placed on the Irradiation Table and Subjected to

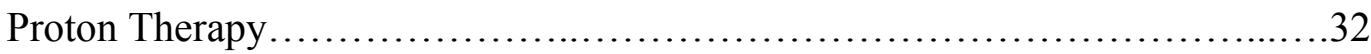




\section{CHAPTER 1 INTRODUCTION:}

\subsection{Overview}

Radiation therapy is one of the primary treatment modalities employed for the ablation of various tumors in the clinic. ${ }^{1}$ Ideally, one can enhance therapeutic advantages of ionizing radiation by maximizing the sparing of the volume of healthy tissues that otherwise get exposed to XRT. At present, most external beam radiotherapy (EBRT) is administered using high-energy photons (e.g. X-rays), which characteristically deliver exit doses. As a result of which there is significant amounts of dose bath delivered to normal tissues lying either adjacent or towards the distal end of the target. This can lead to side effects, including radiation-induced toxicity, in healthy tissues ${ }^{2}$.

Radiation doses are typically delivered in fractions of 2-5 Gy dose/day (conventional fractionated radiotherapy) leading to a cumulative dose in the range of 20 - 70 Gy for the entire treatment course $(1 \mathrm{~Gy}=1 \text { Joule energy absorbed by a } 1 \mathrm{~kg} \text { mass })^{3,4}$. Following the development of sophisticated imaging techniques and beam delivery modalities, proton beam therapy has found increased application in the treatment of cancer ${ }^{5}$. Proton beam therapy can therefore benefit from in vivo monitoring the dose delivered to different tissues during each fractionated treatment resulting in high efficacies and low toxicities. Currently employed dosimeters in the clinic (e.g. thermoluminescent diodes or TLDs, polymer gels, MOSFETs, radiographic film, etc.) require specialized equipment, can be cumbersome to operate, exhibit energy dependence, can require expensive fabrication processes, do not conform to human anatomical features, and / or use 
sophisticated and expensive visualization modalities including magnetic resonance

imaging (MRI) ${ }^{6-8}$ In many cases, they may also fail to provide information about the delivered dose at more than one point in the patient and the dose may be reported with insufficient spatial resolution. A novel dosimeter that can overcome these limitations, while demonstrating robust performance, can result in safe and effective monitoring radiation doses in proton therapy, potentially leading to improved patient outcomes.

\subsection{Literature Review}

Lately, gold and silver nanoparticles have found a lot of potential applications in biomedical field owing to their surface plasmon resonance properties ${ }^{9}$. Typically, these nanoparticle size ranges from $1-100 \mathrm{~nm}$. These nanoparticles have been found to have a tendency of accumulating near tumor sites and hence have been used as imaging agents in radiation oncology. It has also been found that gold nanoparticles of optimal sizes can enhance CT imaging and radiotherapy in real time. Surface-enhanced Raman Scattering are enhanced because of the oscillating surface plasmons in these nanoparticles eventually resulting in increased efficacy of biological and chemical sensing. Stable free radicals are formed in amino acids can be detected using electron spin resonance (ESR) ${ }^{10}$. This free radical formation is induced when alanine powder and alanine blended with polymeric binders are used. These dosimeters are typically used when lower energies of the $\mathrm{keV}$ order are employed. The ESR signal response obtained is proportional to the number of free radicals formed and this in turn is used to report the radiation dose. Systems like these are widely used in biological dosimetry. They also serve as a reference point for commercially available dosimeters. Doping with high $\mathrm{Z}$ microscale materials 
are found to enhance sensitivity of the alanine systems to X-rays ${ }^{11}$. This is because, incorporating the plasmonic particles in the matrix increase the dose enhancement factor (ratio of the mass absorption coefficient of the nanocomposite to that of pure alanine). These metallic nanoparticles, upon exposure contribute to an increase in the generation of free radicals within the alanine matrix. Nanocomposite powders were made by adding pre-synthesized nanoparticles to an aqueous alanine solution before drying at $40^{\circ} \mathrm{C}$. When irradiated using a $90 \mathrm{keV}$ beam, these nanocomposites displayed enhanced peakto-peak amplitude of the ESR spectra. Interestingly, when the nanoparticle concentration was increased from $0.01 \%$ to $1 \%$ AgNP, the DEF decreased. This could be attributed to agglomeration of particles at higher concentrations. Gold nanoparticles were seen to show the same behavior when employed. These nanocomposites with a linear response between 1 - 50 Gy have been seen to demonstrate nanoparticle size stability, improved sensitivity and homogeneity. Although ESR is a sophisticated detection technique, one limitation in this detection technique is that it requires trained professionals on specialized equipment. This can be a limitation in translating this technology towards clinical radiotherapy.

Many nanoscale systems and molecules are being investigated as radiation dosimeters for conventional fractionated radiotherapy ${ }^{12}$. Although they exhibit potential for translation into clinical radiotherapy and implantable applications, additional studies have to be conducted on the reproducibility, biocompatibility, sensitivity, stability and/or toxicity of these systems. Recent studies carried out so far have demonstrated that only the 
peripheral dose delivered is measured and there is no direct contact of the dosimeter with tissue $^{13}$.

\subsection{Motivation}

Proton beam therapy is an alternate form of radiation therapy in which particles (protons) instead of high-energy photons are delivered to the tumor, potentially leading to greater control and precision over dose deposition at the disease site. ${ }^{14}$ This can lead to decreased damage to the surrounding tissue and hence fewer side effects post radiation treatment. This is primarily due to the unique dose deposition characteristics of protons known as the Bragg peak. ${ }^{15}$ As the protons enter the patient's body they lose their kinetic energy in collisions with the electrons in the patient's body. As the protons slow down their interaction cross section with electrons increases steadily until it reaches a sharp maximum shortly before the protons come to rest. This sharp maximum gives rise to the dosimetric Bragg peak. ${ }^{16}$

The major advantage of protons over photons in conventional radiotherapy is that photons have a tendency to deposit energy throughout as they travel through the tissue whereas protons deposit maximum at a certain depth and lose their energy ${ }^{17}$. This was explained by William Bragg who found out that energy lost by the charged particle is inversely proportional to the square of its velocity. The velocity of the particles decreases as they travel through mass. The range of proton energy used gives a much flatter peak and hence can be used to target a larger volume of tumor. Hence, a maximum dose deposition occurs incase of proton therapy as compared to photons in radiotherapy. The 
Linear Accelerator (LINAC) used in conventional radiation therapy for protons has a maximum dose depth limitation of $3 \mathrm{~cm}$ while the proton gantry used for proton beam irradiation can deliver a dose upto $32 \mathrm{~cm}$. Also, when compared to X-ray beams, proton beams do not have an exit dose. Therefore, less damage is done to the surrounding tissues and hence less side effects from irradiation.

In this work, a hydrogel based plasmonic nanosensor was made to detect therapeutic levels of radiation doses using proton beam therapy. The intensity of pink color seen because of the gold nanoparticles formed is used as an indicator representing each dose level. These gels were quantifies using UV-visible spectroscopy and a linear calibration curve was obtained for clinically relevant doses. Surfactants of different chain length were employed to optimize the system. The hydrogel system created was robust, less cumbersome and was able to be contoured according to the patient's requirement. 


\section{CHAPTER 2}

\section{INTRODUCTION}

Recent advances in molecular and nanoscale systems offer novel possibilities for radiation dosimeters $^{7}$. Ionizing radiation causes formation of free radicals in water following hydrolysis. We employed this phenomenon in concert with effective templating molecules (e.g. aliphatic surfactants) to engender the formation of plasmonic (gold and gold-silver) nanoparticles from their respective metal ion formulations. ${ }^{12,18-20}$ The formation of plasmonic nanoparticles in liquid or gel formulations is accompanied by a visible color change which is distinct from the original metal ion formulation, which is colorless. Here, we report, for the first time, a colorimetric approach for the rapid detection of therapeutic levels (0-3 Gy $\mathrm{RBE})$ of proton irradiation. The extent of the color intensity depends on the dose of protons delivered to the gel and can be used for quantitative dose determination. To our knowledge, this is the first colorimetric nanosensor for detecting and predicting proton doses and has high potential for translation to clinical proton beam radiotherapy. 


\section{EXPERIMENTAL}

Materials. Gold(III) chloride trihydrate $\left(\mathrm{HAuCl} 4.3 \mathrm{H}_{2} \mathrm{O}\right)$, decyltrimethylammonium bromide $\left(\mathrm{C}_{10} \mathrm{TAB}\right)(\geq 98.0 \%$; non-aqueous titration grade), dodoceyltrimethylammonium bromide $\left(\mathrm{C}_{12} \mathrm{TAB}\right)(\geq 98 \%)$, myristyltrimethylammonium bromide $\left(\mathrm{C}_{14} \mathrm{TAB}\right)(\geq 99 \%)$, Lascorbic acid (AA) and agarose were purchased from Sigma-Aldrich. Cetyltrimethylammonium bromide $\left(\mathrm{C}_{16} \mathrm{TAB}\right)$ was procured from MP Chemicals. The chemicals received from the vendors were not purified further. MilliQ water (18.2 MS.cm) was used as solvent for all experiments.

Preparation of the Precursor Hydrogel. $\mathrm{HAuCl}_{4}(30 \mu \mathrm{L}$ of $10 \mathrm{mM}$ solution) was mixed

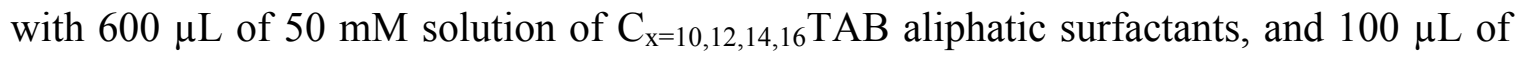
the above mixture were discarded. Heated aqueous agarose $(500 \mu \mathrm{L}$ of $5 \% \mathrm{w} / \mathrm{v})$ was added to the gold-surfactant solution. 24 well plates (diameter $\sim 16 \mathrm{~mm}$ ) were used to set the liquid mixture $(650 \mu \mathrm{L})$ and form gels with a thickness of $\sim 3 \mathrm{~mm}$. Ascorbic Acid (650 $\mu \mathrm{L}$ of $10 \mathrm{mM}$ solution) was allowed to diffuse into the gel for 10 minutes, resulting in the formation of translucent gel discs. These discs were used for irradiation studies as precursor hydrogels.

Proton Beam Irradiation. All CT simulations of the phantom based setup and proton beam irradiations were conducted at the Proton Beam Therapy Center at Mayo Clinic Hospital, Phoenix, AZ. CT simulations were performed using the SOMATOM Definition AS (Siemens Healthcare, Erlangen, Germany), and spot-scanning based proton treatment plans were created using the Eclipse (Varian Medical Systems, Palo Alto, CA) treatment 
planning system (version PCS 13.7) (TPS). Proton irradiations were delivered using the PROBEAT-V Proton Beam Therapy System (Hitachi, Ltd., Tokyo, Japan). Proton beam therapy doses are customarily prescribed and reported in relative biological effectiveness (RBE) - weighted absorbed dose $\left(\mathrm{D}_{\mathrm{RBE}}\right)$. In this work, in order to obtain physical dose D_RBE values may simply be divided by a constant factor of 1.1 .

Gel samples were placed in the inner wells of a 24-well plate, which was placed on the table with $5 \mathrm{~cm}$-thick acrylic blocks placed above and below it. A CT simulation of the phantom was performed with slice thicknesses of $2 \mathrm{~mm}$. A single Field Uniform Dose based treatment plan was designed in order to deliver $0.5 \mathrm{~Gy}_{\mathrm{RBE}}$ uniformly across the central wells. The treatment was optimized such that the $99 \%$ of the dose reporting reference volume received $100 \%$ of the dose. In order to deliver larger doses to these gel samples, sequential treatment plans were generated by simply scaling the doses to higher $\mathrm{D}_{\mathrm{RBE}}$ levels: $0.5,1.0,1.5,2.0,3.0,4.0$ and 5.0 GyRBE. These doses delivered to our samples were validated with another reference film dosimeter. A piece of Gafchromic EBT3 film (Ashland, Bridgewater, NJ) was placed directly below the well plate during irradiation of the gel with 2.0 Gy $\mathrm{RBE}$. Reference dosimetry using these calibrated gafchromic films matched the TPS calculated doses to within $+/-2.5 \%$. While the irradiation times ranged between 41 seconds for the $0.5 \mathrm{~Gy}_{\mathrm{RBE}}$ dose and 86 seconds for the 5.0 Gy $\mathrm{GBE}_{\mathrm{RB}}$ dose, dose rate dependence of these dosimeters has not been investigated in this particular study. 
Plasmonic Gel Dosimetry on an Anthropomorphic Child Phantom. A CT simulation, using a slice thickness of $1 \mathrm{~mm}$ and a pitch of 1.0, was performed on an ATOM 704 anthropomorphic phantom (CIRS Inc., Norfolk, VA), which models a 1-year-old infant. Three radio-opaque markers were placed at isocenter, and two more were placed at the head and foot to ensure a reproducible setup. A plan was created whereby a posterioranterior field was used to deliver a prescription $\mathrm{D}_{\mathrm{RBE}}$ of $1.8 \mathrm{~Gy}_{\mathrm{RBE}}$ to a target encompassing the spine. The phantom was irradiated with gel samples placed on the table at various points beneath it, providing a measurement of the skin dose to the phantom.

Absorbance Spectroscopy. Following irradiation with different proton doses, the absorbance spectra of the gel samples were measured for wavelengths ranging from 300 to $990 \mathrm{~nm}$ with a step size of $10 \mathrm{~nm}$ using a BioTek Synergy 2 plate reader. All absorbance measurements were carried out at 2 hours following irradiation, because the travel time from the Mayo Clinic to ASU can vary. However, the color change was seen as early as 15 minutes post irradiation in most cases. The absorbance values obtained were offset by subtracting the wavelength at $990 \mathrm{~nm}$. The peak between 500-600 nm was used as an indicator for the formation of gold nanoparticles. A maximum absorbance value between 500-600 nm vs. proton dose was plotted for all surfactants.

Image Processing. A Canon EOS 1100D camera was used to acquire all gel images. The Fotor Photo Editor application was used to crop the images to the desired size, but no further editing was carried out. All pictures reported in this article were acquired for 
visualization alone and not used for quantification of the dose response, which was carried out using absorbance analysis.

Transmission Electron Microscopy. The irradiated sample was kept at room temperature overnight for air drying. The dried sample was soaked in epoxy resin. Thin slices of the cured epoxy-containing sample were sectioned using an ultramicrotome. These thin samples were imaged using a Philips CM 12 Transmission electron microscope.

Statistical Analyses. All experiments were carried out in triplicate unless otherwise stated. Statistical analysis calculations were carried out using Microsoft Excel and data are expressed as the mean of these independent experiments \pm one standard deviation. 


\section{RESULTS AND DISCUSSION}

The ability to detect proton doses administered to tissues can have significant implications for improving treatment outcomes in radiotherapy. To this end, a robust nanosensor that can reliably detect doses at the intended target as well as nearby tissues can enhance the efficacy of radiotherapy, which can lead to improved patient outcomes. Here, we report our studies on a gel-based colorimetric nanosensor that can detect doses employed for fractionated proton radiotherapy in the clinic. The nanosensor works on the principle that exposure of a precursor hydrogel to high-energy radiation (e.g. photons) or particles (e.g. protons) results in the formation of free radicals upon hydrolysis (water splitting), which, in turn, reduce the encapsulated gold ions to gold nanoparticles within the matrix (Figure 2.3.1.). ${ }^{12,19}$

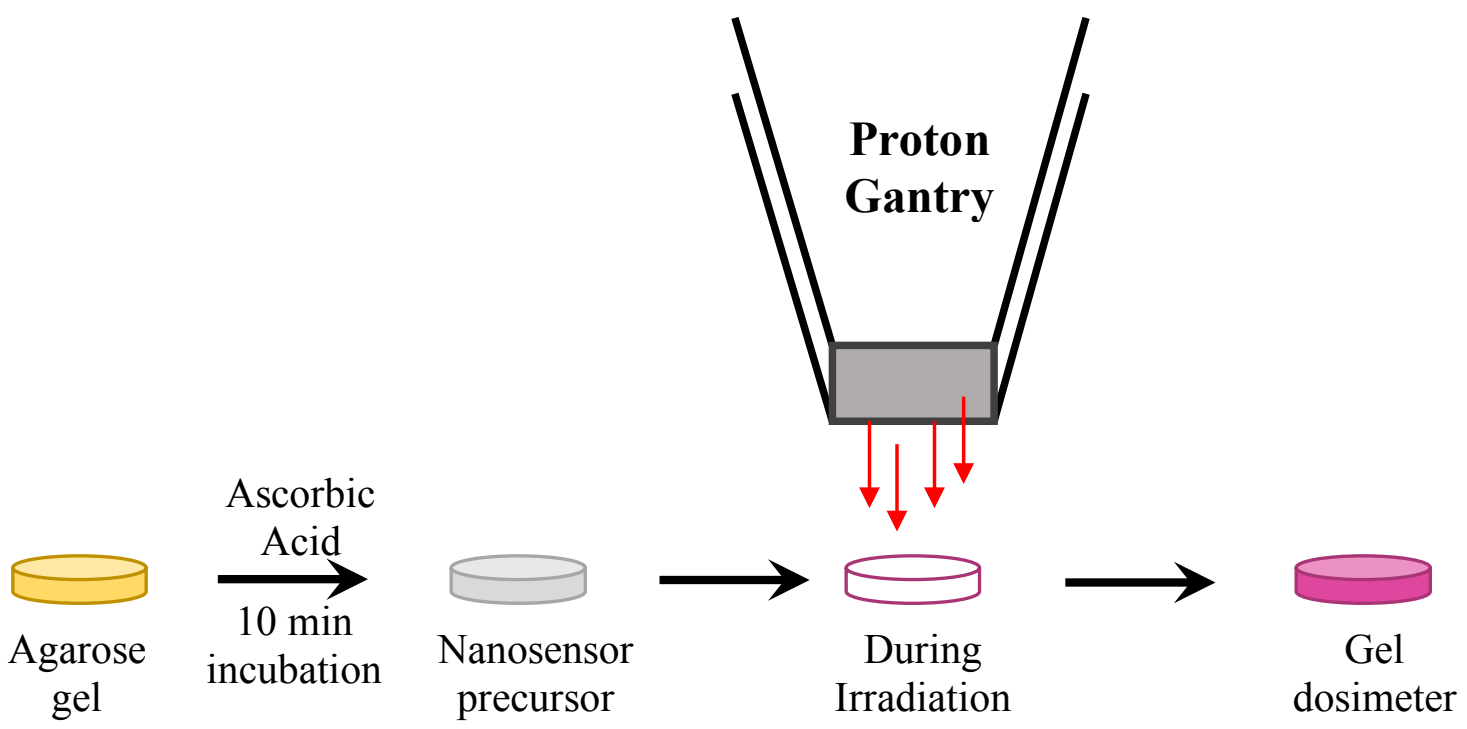


Figure 2.3.1. Schematic of hydrogel nanosensor dosimeters for proton beam therapy. Cylindrical hydrogel discs, $16 \mathrm{~mm}$ diameter and $3 \mathrm{~mm}$ height, are formulated with 10 $\mathrm{mM} \mathrm{HAuCl}_{4}, 50 \mathrm{mM} \mathrm{C}_{\mathrm{x}} \mathrm{TAB}(\mathrm{x}=10,12,14$ or 16$)$ and $5 \%(\mathrm{w} / \mathrm{v})$ agarose. Just prior to irradiation, $10 \mathrm{mM}$ ascorbic acid is added from the top and allowed to diffuse into the gel for 10 minutes. A characteristic maroon color is seen post irradiation due to formation of gold nanoparticles within the gel matrix.

Initially, gold exists as trivalent $\mathrm{Au}(\mathrm{III})$ ions along with the cationic surfactant molecules within the heated agarose solution. These $\mathrm{Au}(\mathrm{III})$ metal ions are then reduced to monovalent $\mathrm{Au}(\mathrm{I})$ ions using ascorbic acid as the reducing agent. ${ }^{21}$ The reduction potential of $\mathrm{Au}(\mathrm{I})$ is higher than that of $\mathrm{Au}(\mathrm{III})$, which increases the thermodynamic favorability of zerovalent gold ion or $\mathrm{Au}(0)$ formation. ${ }^{22,23}$ These $\mathrm{Au}(0)$ ions are thought to nucleate and grow to form gold nanoparticles; the cationic surfactant used in the formulation $\left(\mathrm{C}_{\mathrm{x}} \mathrm{TAB} ; \mathrm{x}=10,12,14\right.$, or 16$)$ likely stabilizes the gold nanoparticles formed and may also play a role in templating the nanoparticles.

Irradiation of $\mathrm{Au}(\mathrm{I})$-containing agarose gels with high-energy proton particles can facilitate splitting of water molecules in the hydrogel, which, in turn, can result in the formation of e-, $\mathrm{H}^{\cdot}$ and $\mathrm{OH}^{\cdot}$ free radicals. ${ }^{24}$ Of these, $\mathrm{e}^{-}$and $\mathrm{H}^{\cdot}$ are reducing in nature and help reduce $\mathrm{Au}(\mathrm{I})$ ions to zerovalent $\mathrm{Au}(0)$ ions. Ascorbic acid, an antioxidant, is thought to help quench the oxidizing $\mathrm{OH}^{\cdot}$ radicals formed in the process, ${ }^{25}$ which can further enhance the efficacy of nanoparticle formation. The agarose hydrogels are initially translucent and colorless prior to irradiation, but change color to maroon once exposed to protons due to formation of gold nanoparticles within the matrix, resulting in a visible 
indicator of proton therapy doses. Surfactants of different chain lengths $\left(C_{x}\right.$, where $x=10,12,14$, or $\left.{ }_{16} \mathrm{TAB}\right)$ were employed to facilitate the formation of gold nanoparticles. Water solubility, biocompatibility and ease in formulation of hydrogels were some of the major factors influencing the selection of agarose as the gel matrix.

A number of control experiments were carried out in order to investigate the performance of the gel nanosensor system. An intense yellow color of the hydrogel was observed following the mixture of $\mathrm{HAuCl}_{4}$ and $\mathrm{C}_{\mathrm{x}} \mathrm{TAB}(\mathrm{x}=10,12,14$ or 16$)$ with heated agarose. The observed color is caused by the ligand exchange of $\mathrm{Cl}^{-}$in $\mathrm{AuCl}_{4}^{-}$to $\mathrm{Br}^{-}$present in $\mathrm{C}_{\mathrm{x}} \mathrm{TAB} .^{22}$ It is likely that $\mathrm{AuBr}_{4}{ }^{-}$exists as stable CTA-AuBr${ }_{4}^{-}$metallomicelles within the agarose matrix. ${ }^{22}$ Ascorbic acid reduces $\mathrm{AuBr}_{4}{ }^{-}$to $\mathrm{AuBr}_{2}^{-}$, which indicates conversion of gold ions from the trivalent $\mathrm{Au}(\mathrm{III})$ state to the monovalent $\mathrm{Au}(\mathrm{I})$ state ${ }^{26}$ Ascorbic acid is a weak reducing agent, and thus only partial reduction of the gold (from $\mathrm{Au}(\mathrm{III})$ to $\mathrm{Au}(\mathrm{I})$ ) is possible in the presence of a high concentration of the surfactant. This is because the oxidation potential of the ascorbic acid reduces in micellar environments. ${ }^{27}$ The yellowcolored hydrogels turn colorless once ascorbic acid is added to the hydrogel, which is the precursor hydrogel used in all proton irradiation studies. We suggest that the presence of micelles in our hydrogel system leads to enhanced shielding between $\mathrm{Au}^{+}$ions and ascorbic acid, which retards spontaneous nanoparticle formation.

Irradiation of agarose hydrogels containing $\mathrm{HAuCl}_{4}$ and $\mathrm{C}_{\mathrm{x}} \mathrm{TAB}$ with protons in the absence of ascorbic acid did not induce any color change to the hydrogel (Figure 2.3.2). 

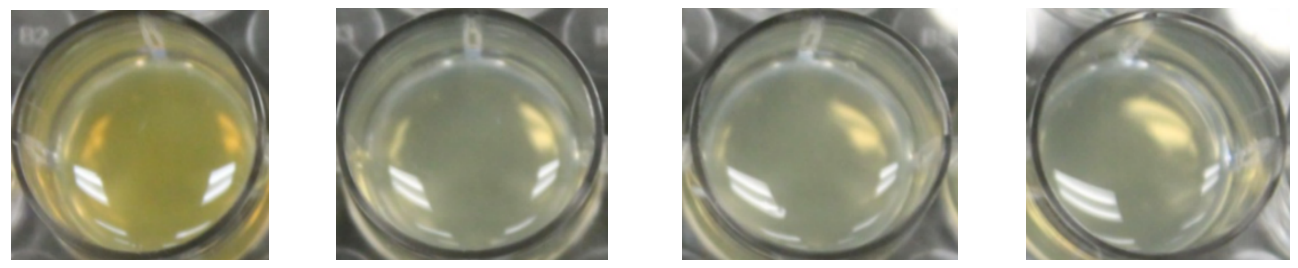

Figure 2.3.2. Images of controls of agarose gels acquired $2 \mathrm{hrs}$ post a $2 \mathrm{~Gy}_{\mathrm{RBE}}$ radiation dose containing $10 \mathrm{mM} \mathrm{HAuCl}_{4}$ and $50 \mathrm{mM} \mathrm{C}_{\mathrm{x}=10,12,14 \& 16}$ TAB surfactant (From Left to Right). No change in color was observed post irradiation. Ascorbic acid was not used in any of the gel formulations.

Similarly, irradiation of gels containing a mixture of $\mathrm{HAuCl}_{4}$ and agarose alone (no ascorbic acid or $\mathrm{C}_{\mathrm{x}} \mathrm{TAB}$ ) did not result in a change in color (Figure 2.3.3).

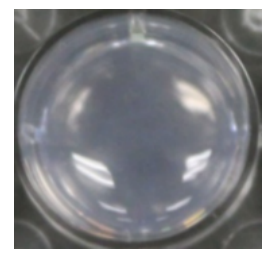

Figure 2.3.3. Image of control of agarose gels acquired $2 \mathrm{hrs}$ post a $2 \mathrm{~Gy}_{\mathrm{RBE}}$ radiation dose containing only $10 \mathrm{mM} \mathrm{HAuCl}_{4}$. No change in color was observed post irradiation. Ascorbic acid was not used in any of the gel formulations.

These results indicate that all components $-\mathrm{HAuCl}_{4}, \mathrm{C}_{\mathrm{x}} \mathrm{TAB}$, ascorbic acid (AA) and agarose - play a key role in the formulation of the plasmonic hydrogel based nanosensor for detecting proton doses. Interestingly, we observed that $\mathrm{C}_{10} \mathrm{TAB}$ shows a slight development of color, which indicates spontaneous nanoparticle formation even in 
absence of radiation. $\mathrm{C}_{10} \mathrm{TAB}(\mathrm{CMC} \sim 65 \mathrm{mM})$ does not form micelles at concentrations employed ( $25 \mathrm{mM})$ in the current system. ${ }^{28}$ This likely leads to low steric hindrance and allows for spontaneous nanoparticle formation, which can be visually observed (Figure 2.3.4.).

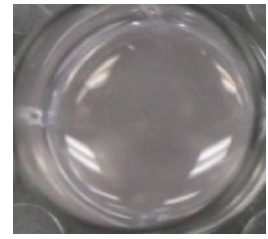

0 Gy

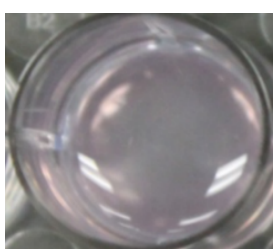

$0.5 \mathrm{~Gy}_{\mathrm{RBE}}$

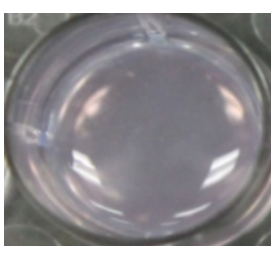

$1 \mathrm{~Gy}_{\mathrm{RBE}}$

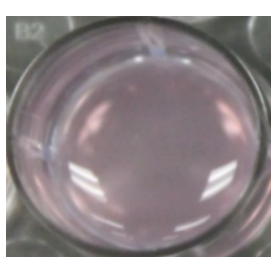

2 Gy $y_{\text {RBE }}$

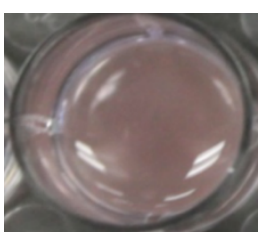

$3 \mathrm{~Gy}_{\mathrm{RBE}}$

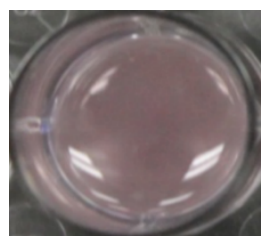

$4 \mathrm{~Gy}_{\mathrm{RBE}}$

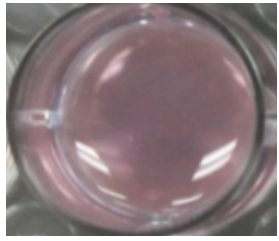

$5 \mathrm{~Gy}_{\mathrm{RBE}}$

Figure 2.3.4. Images of hydrogel nanosensors containing $50 \mathrm{mM} \mathrm{C}_{10} \mathrm{TAB}$ irradiated with different doses of proton beams as indicated. All gels contain $10 \mathrm{mM}$ $\mathrm{HAuCl}_{4}$ and $10 \mathrm{mM}$ ascorbic acid. All images were taken 2 hours after irradiation of gels with protons.

All surfactants employed were able to facilitate and template the formation of gold nanoparticles when exposed to the therapeutic doses of proton irradiation (0-5 Gy $\left.\mathrm{RBE}_{\mathrm{RE}}\right)$. A 
characteristic maroon color of gold nanoparticles was visible post irradiation in the hydrogels (Figures 2.3.5.).

(A)
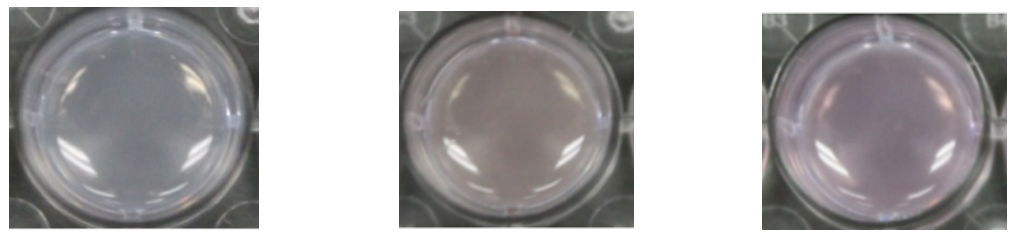

$0 \mathrm{~Gy}_{\mathrm{RBE}}$

$0.5 \mathrm{~Gy}_{\mathrm{RBE}}$

$1 \mathrm{~Gy}_{\mathrm{RBE}}$

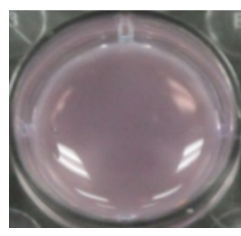

2 Gy

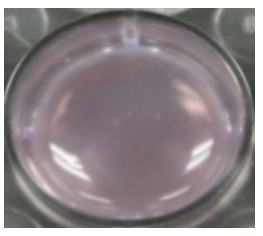

$3 \mathrm{~Gy}_{\mathrm{RBE}}$

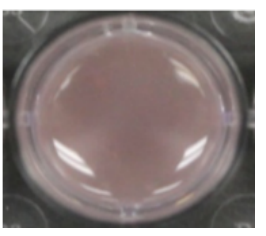

4 GyrBe

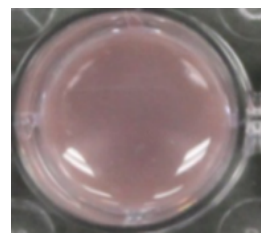

5 Gy

(B)

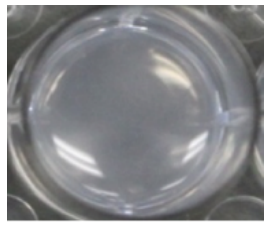

$0 \mathrm{~Gy}_{\mathrm{RBE}}$

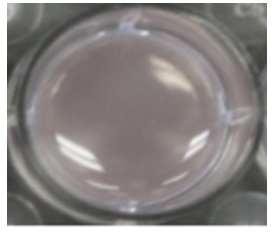

$0.5 \mathrm{~Gy}_{\mathrm{RBE}}$

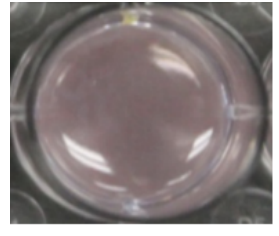

$1 \mathrm{~Gy}_{\mathrm{RBE}}$

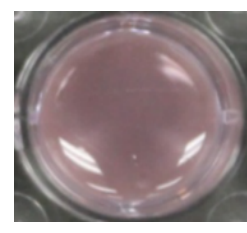

$2 \mathrm{~Gy}_{\mathrm{RBE}}$

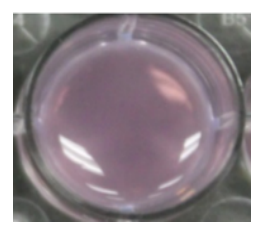

$3 \mathrm{~Gy}_{\mathrm{RBE}}$

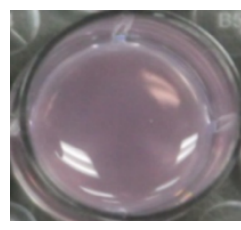

$4 \mathrm{~Gy}_{\mathrm{RBE}}$

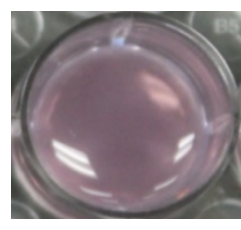

$5 \mathrm{~Gy}_{\mathrm{RBE}}$ 
(C)
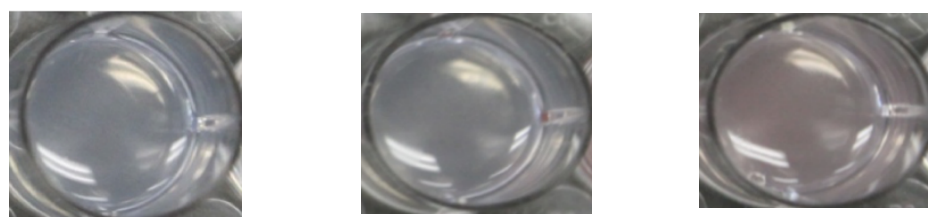

$0 \mathrm{~Gy}_{\mathrm{RBE}}$

$0.5 \mathrm{~Gy}_{\mathrm{RBE}}$

$1 \mathrm{~Gy}_{\mathrm{RBE}}$

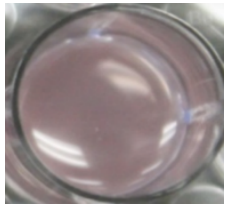

2 GyrBe

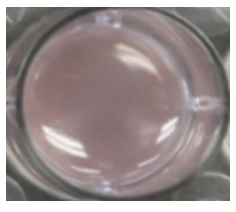

$3 \mathrm{~Gy}_{\mathrm{RBE}}$

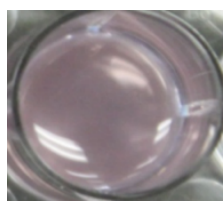

$4 \mathrm{~Gy}_{\mathrm{RBE}}$

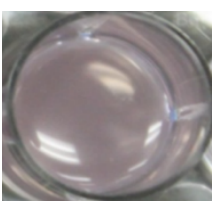

$5 \mathrm{~Gy}_{\mathrm{RBE}}$

Figure 2.3.5. Images of hydrogel nanosensors containing (A) $50 \mathrm{mM} \mathrm{C}_{12} \mathrm{TAB}$, (B) 50 $\mathrm{mM} \mathrm{C}_{14} \mathrm{TAB}$ and (C) $50 \mathrm{mM} \mathrm{C}_{16} \mathrm{TAB}$ surfactants, irradiated with different doses of proton beams as indicated. All gels contain $10 \mathrm{mM} \mathrm{HAuCl}_{4}$ and $10 \mathrm{mM}$ ascorbic acid.

All images were taken 2 hours after irradiation of gels with protons.

The color in the hydrogels irradiated with doses more than $1 \mathrm{~Gy}_{\mathrm{RBE}}$ was visually observable 10 min. after exposure to radiation. Low dose ( $0.5 \mathrm{~Gy}_{\mathrm{RBE}}$ and $\left.1 \mathrm{~Gy}_{\mathrm{RBE}}\right)$ irradiation required longer times $(\sim 20 \mathrm{~min}$.) for development of the maroon color. The increase in color intensity is directly dependent on the generation of free radicals which increases as the dose of the proton irradiation increases. This results in an increase in the formation of gold nanoparticles upon irradiation. Formation of gold nanoparticles was further visualized using transmission electron microscopy (TEM; Figure 2.3.6.); non- 
homogenous particle distribution was observed with particles ranging from $20-100 \mathrm{~nm}$ in diameter.

(A)

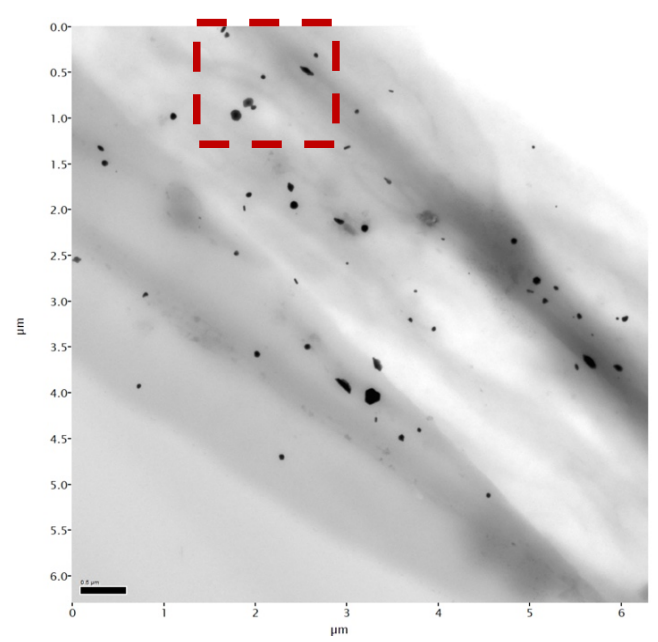

(B)

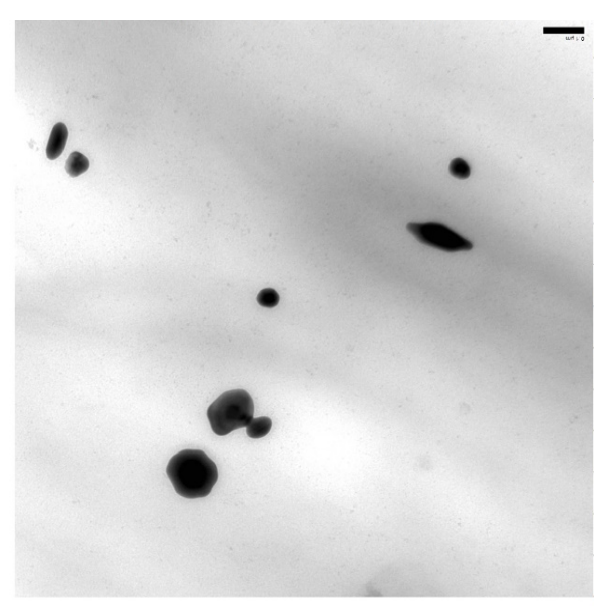

Figure 2.3.6. Transmission Electron Microscopy (TEM) micrographs of gold nanoparticles with $\mathrm{C}_{12} \mathrm{TAB}$ as surfactant irradiated with $2 \mathrm{~Gy}_{\mathrm{RBE}}$ radiation dose. (A) Lowmagnification image depicting presence of gold nanoparticles in the dried hydrogel. (B) High-magnification image of the highlighted region in Figure A.

The absorbance of hydrogels was quantified using UV-vis spectroscopy, 2 hours post irradiation with protons (Figure 2.3.7.). A characteristic spectral peak corresponding to the presence of gold nanoparticles was observed at $\sim 520 \mathrm{~nm}$. 
(A)

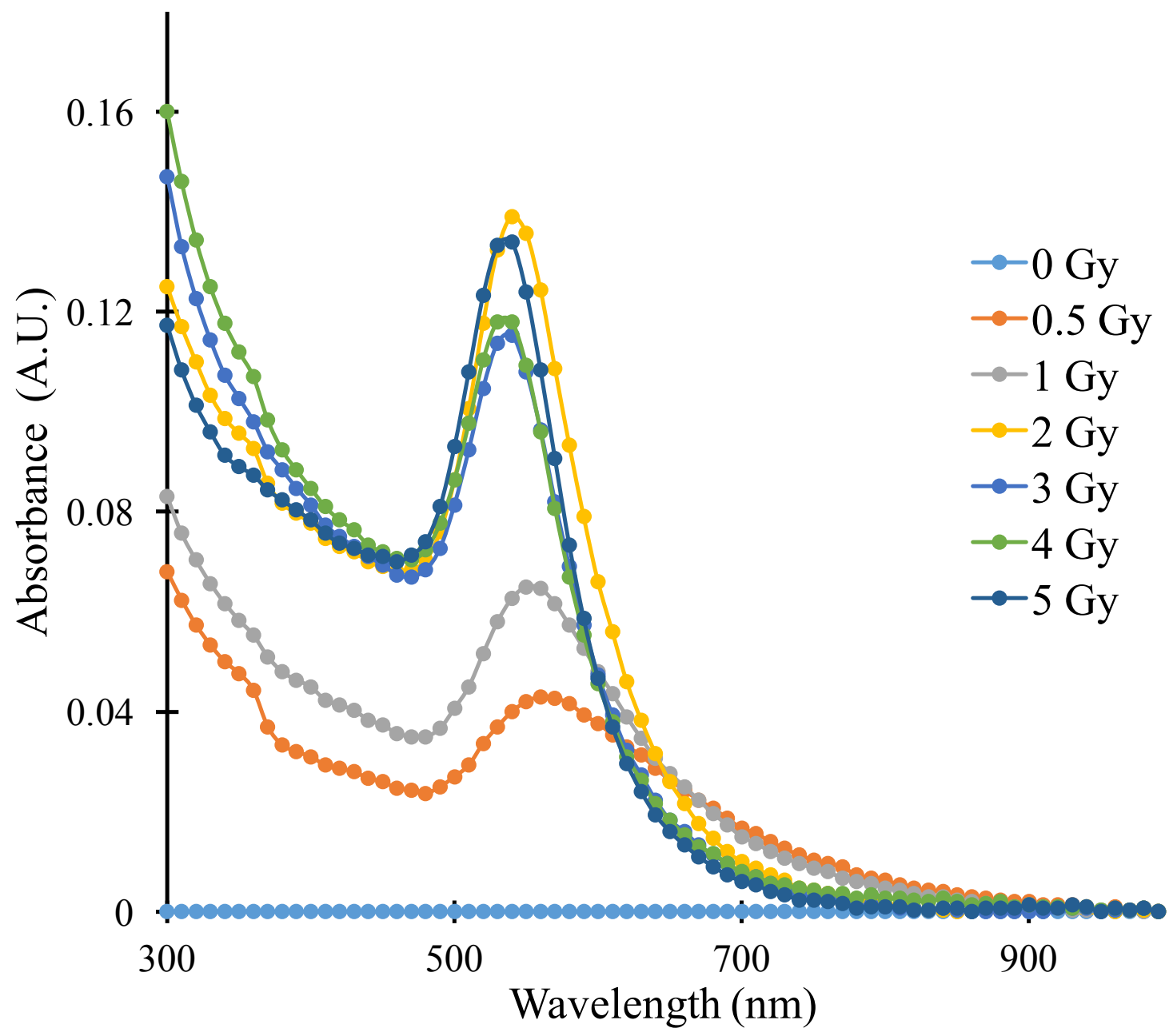


(B)

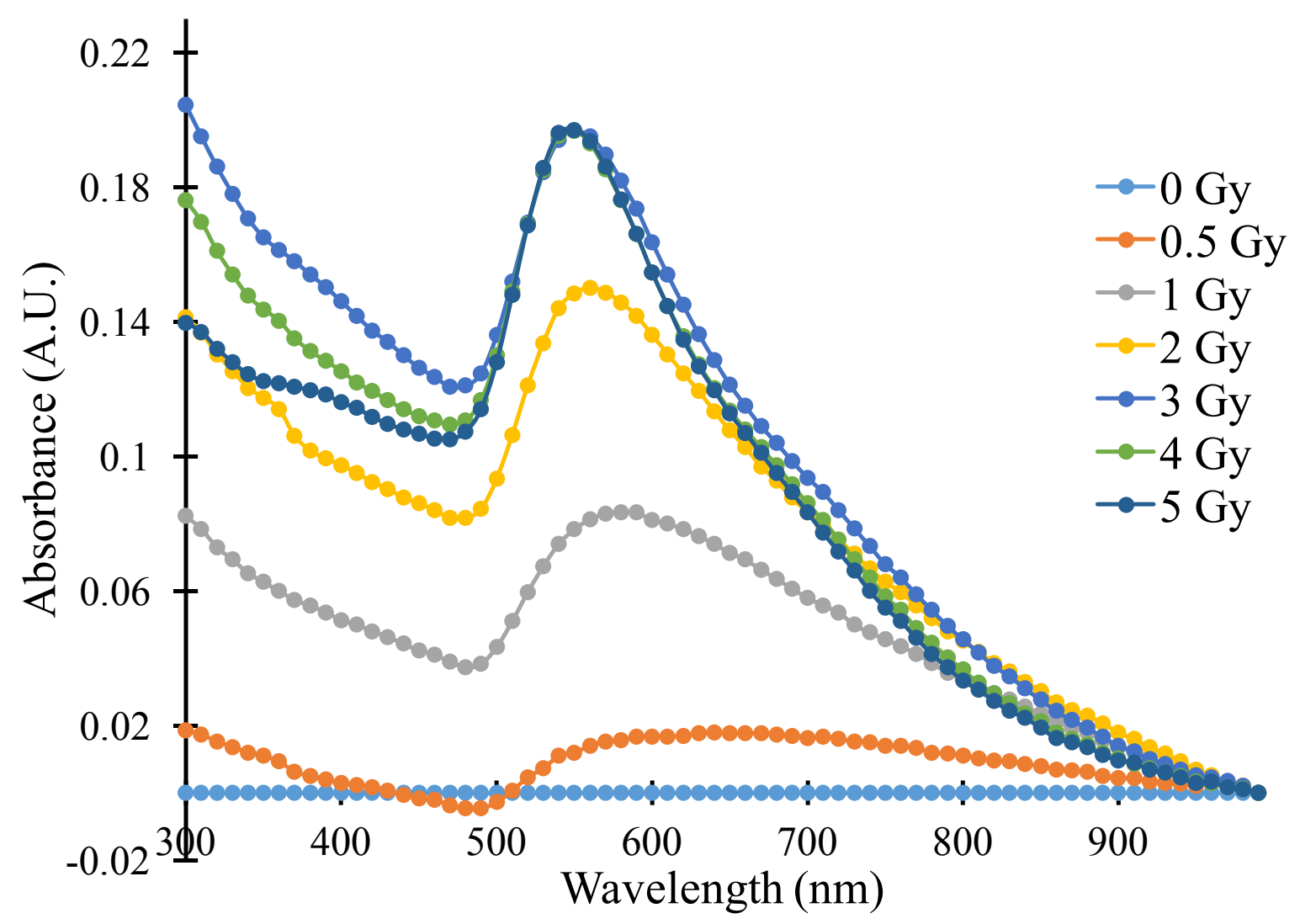


(C)

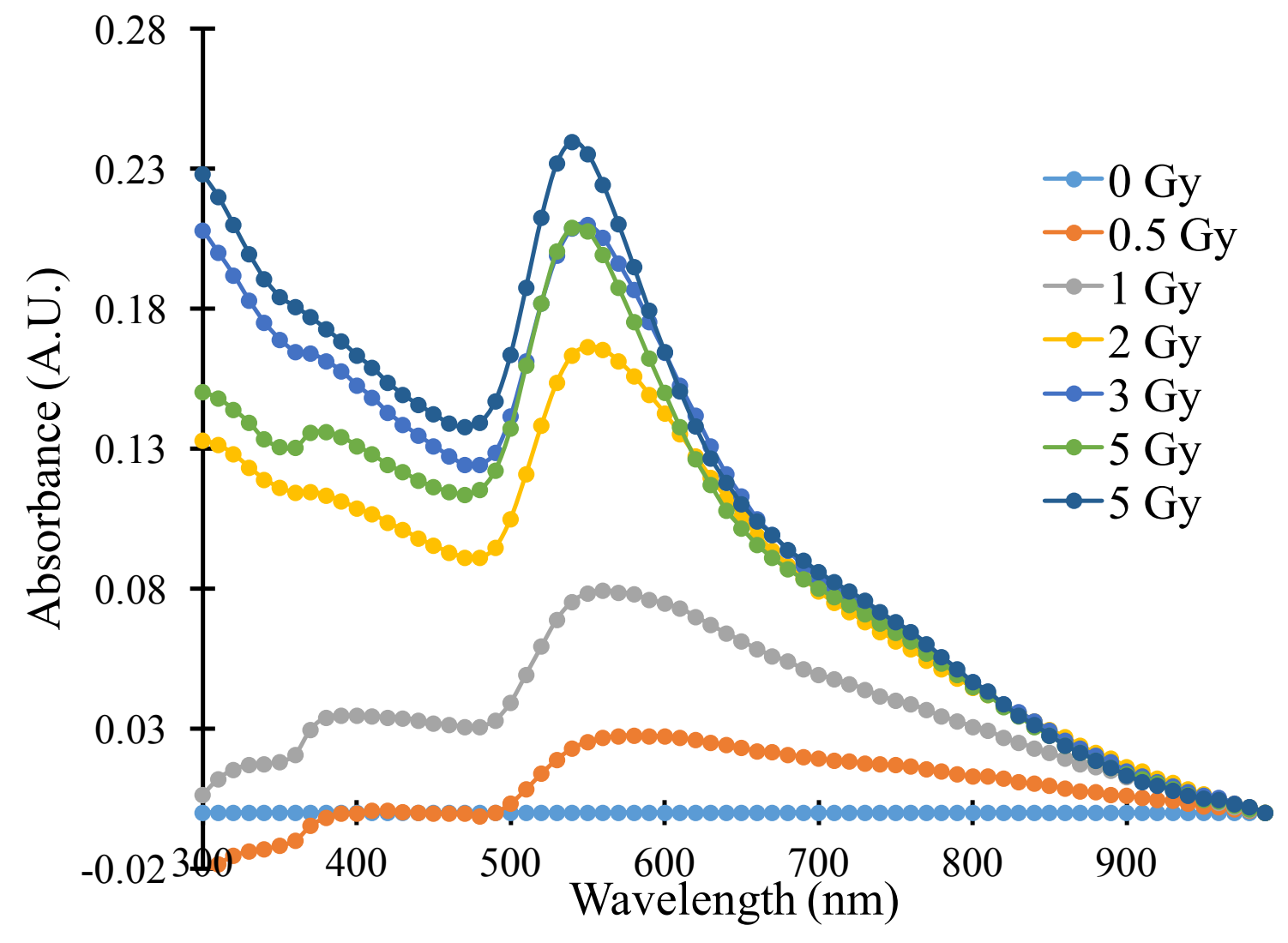


(D)

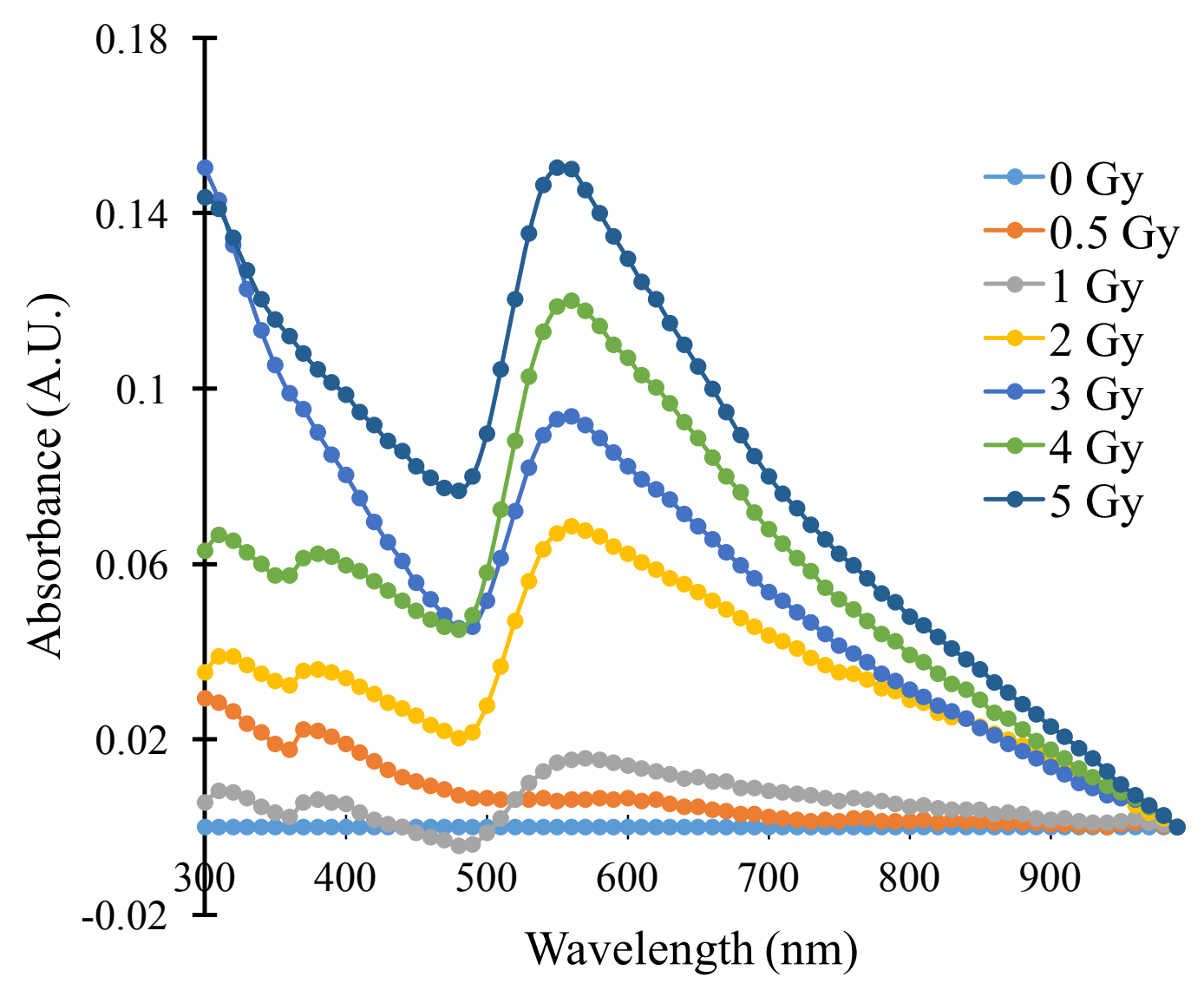

Figure 2.3.7. Absorbance spectra of nanosensor gels containing (A) $\mathrm{C}_{10} \mathrm{TAB}, \mathbf{( B )}$ $\mathrm{C}_{12} \mathrm{TAB},(\mathbf{C}) \mathrm{C}_{14} \mathrm{TAB}$ and (D) $\mathrm{C}_{16} \mathrm{TAB}$ as surfactants post irradiation with proton beams at different doses. Gold nanoparticle formation is indicated by a characteristic peak between $500-600 \mathrm{~nm}$.

No change in color was observed for up to 4 hours, indicating stability of the generated nanoparticles over time (Figure 2.3.8.); gold nanoparticles are known to be stable and we do not anticipate change in the color over longer durations. 
(A)

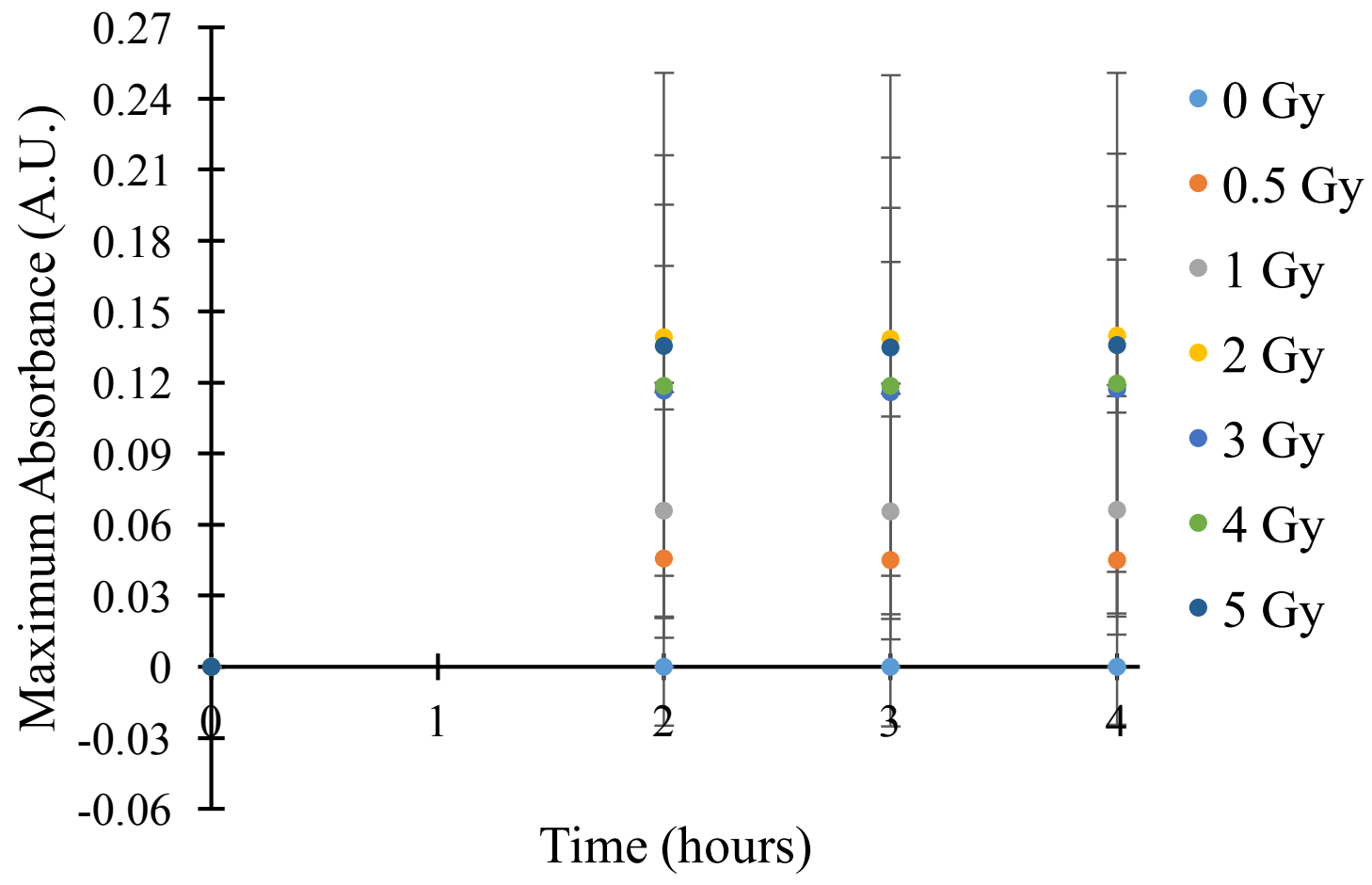


(B)

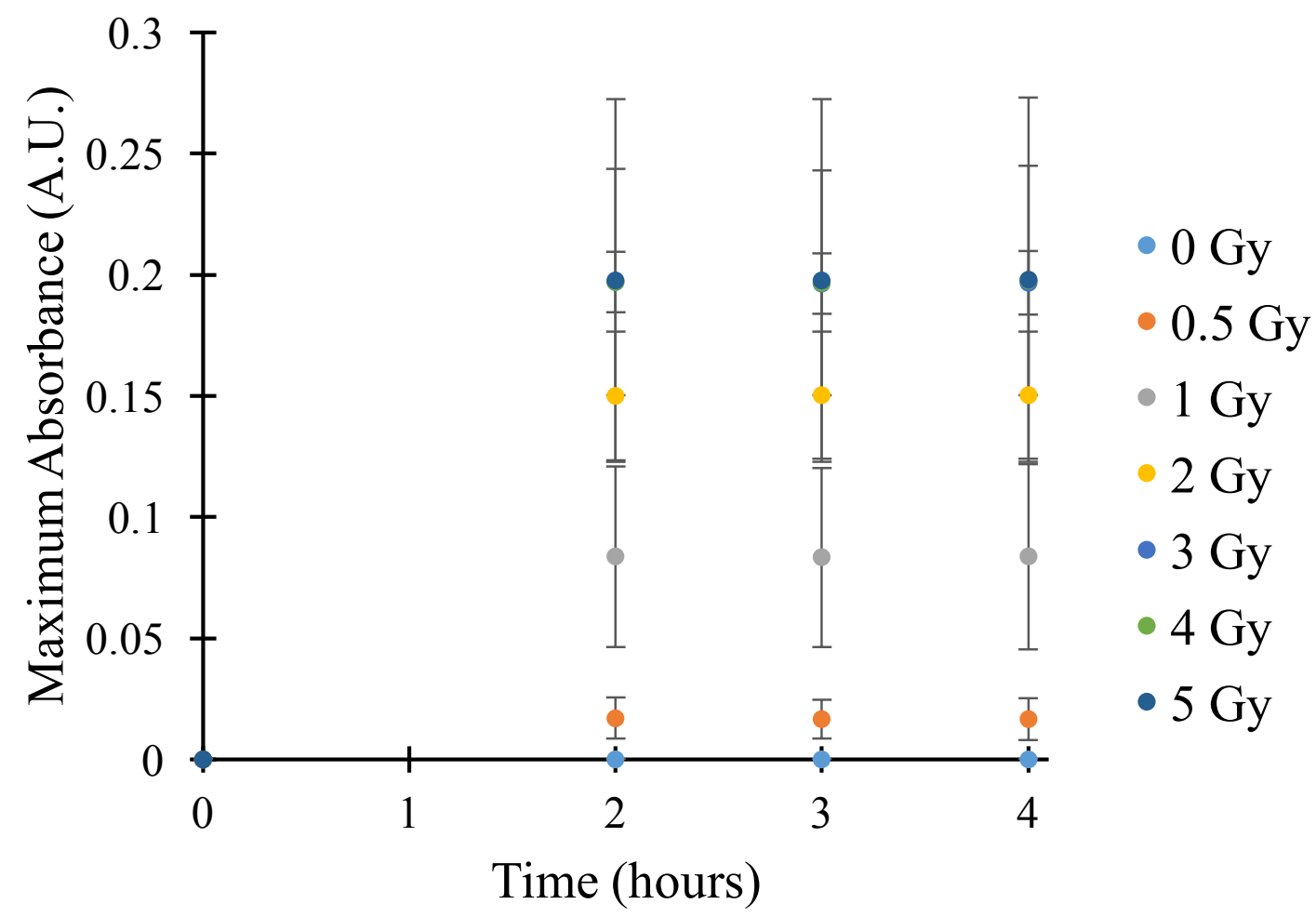


(C)

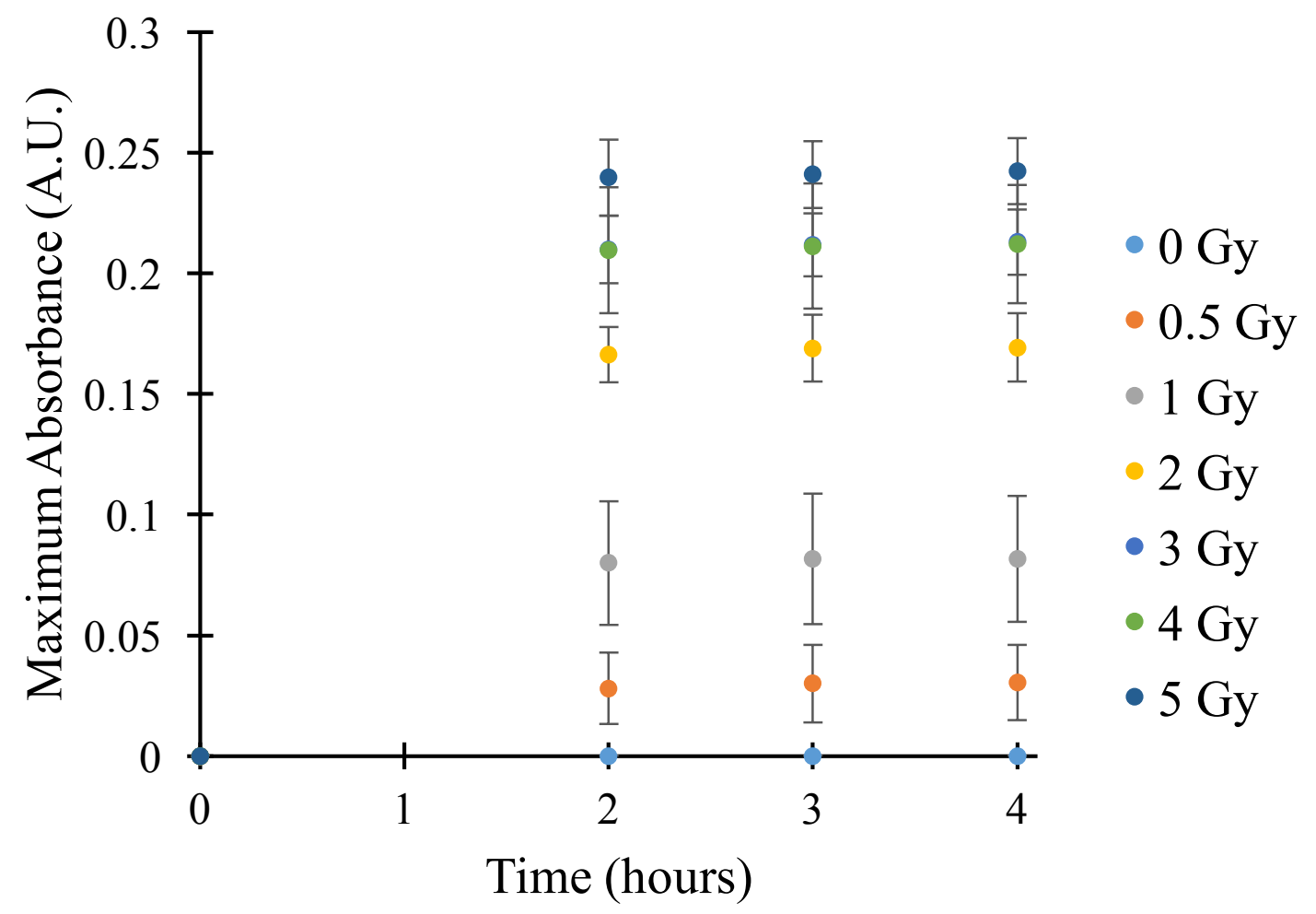


(D)

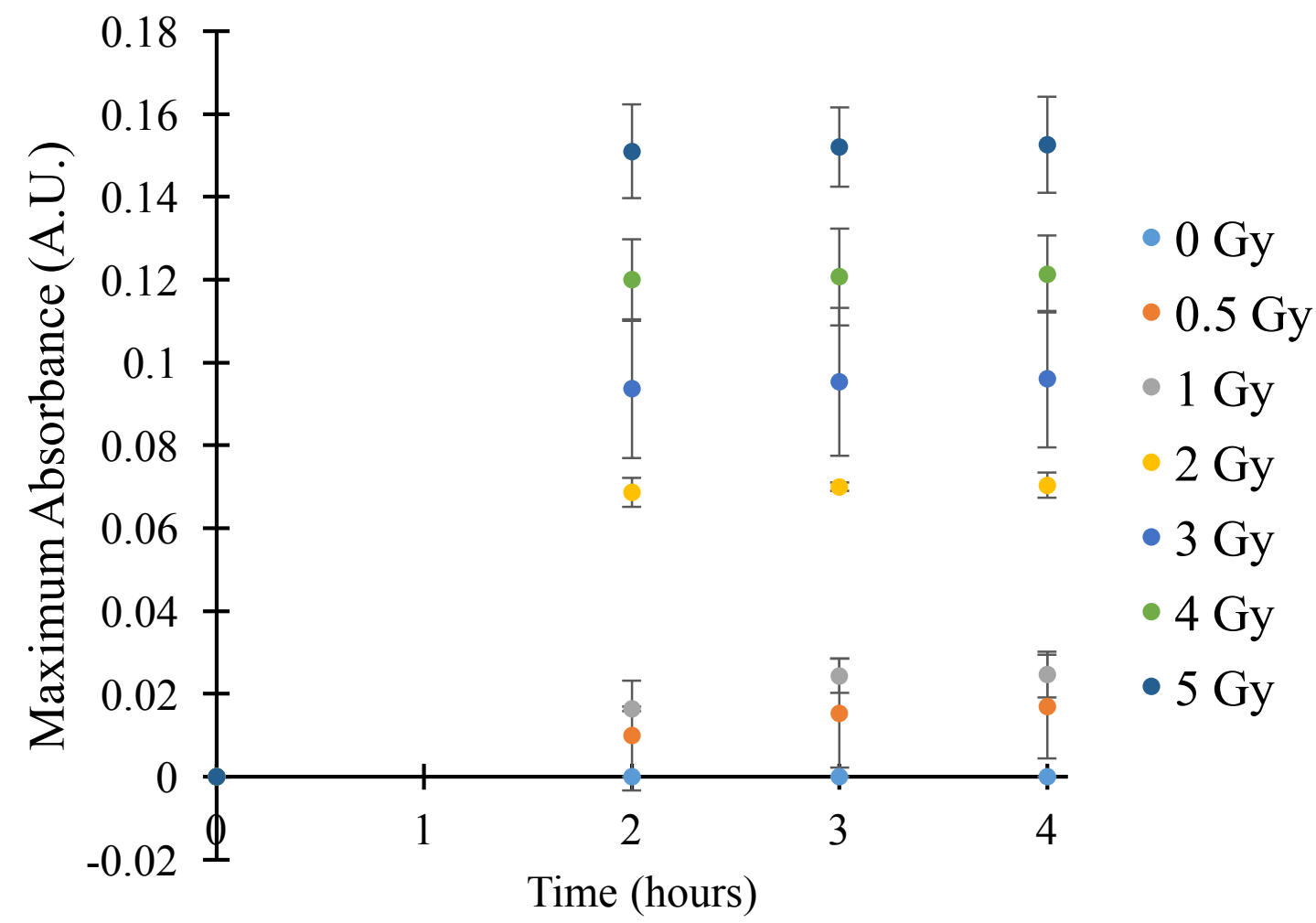

Figure 2.3.8. Kinetics of gold nanoparticles in agarose hydrogels with (A) $\mathrm{C}_{10} \mathrm{TAB}$, (B) $\mathrm{C}_{12} \mathrm{TAB},(\mathbf{C}) \mathrm{C}_{14} \mathrm{TAB}$ and (D) $\mathrm{C}_{16} \mathrm{TAB}$ with protons. Absorbance spectra was measured after $2 \mathrm{hrs}$ post irradiation with the maximum absorbance (between $500-600 \mathrm{~nm}$ ) plotted against time to generate the plot.

A correlation between the administered proton radiation dose and maximum absorbance was plotted between 0 - $5 \mathrm{~Gy}_{\mathrm{RBE}}$ (Figure 2.3.9. and 2.3.10.), which is a range commonly used in conventional fractionated proton beam therapy. 


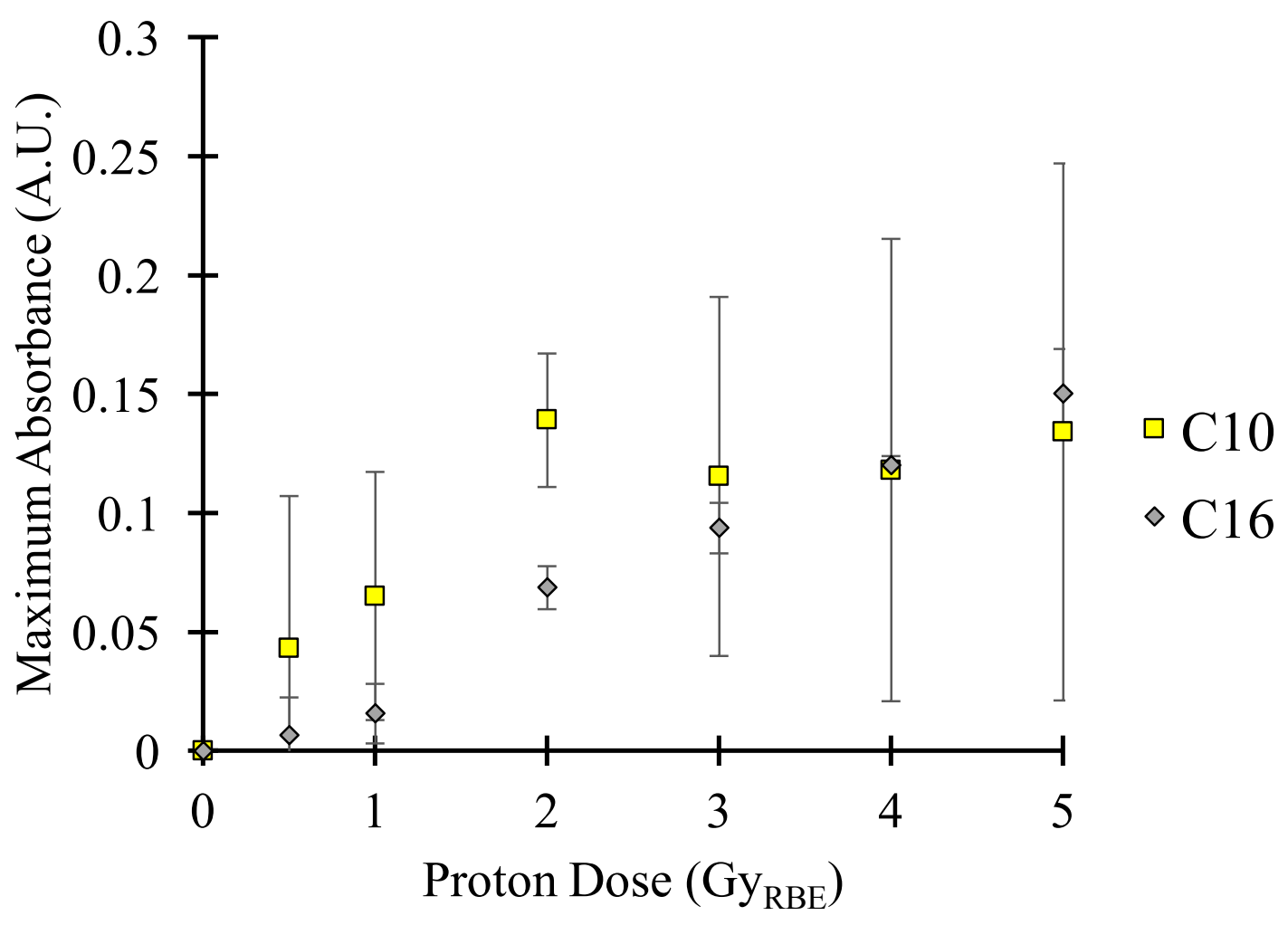

Figure 2.3.9. Absorbance spectra of the nanosensor gel following irradiation with proton beam therapy; A plot depicting maximum absorbance vs radiation dose $2 \mathrm{hrs}$ post irradiation is shown. The formulation of gels with (A) yellow squares representing $\mathrm{C}_{10} \mathrm{TAB}$ surfactant while (B) grey diamonds representing $\mathrm{C}_{16} \mathrm{TAB}$ with $10 \mathrm{mM} \mathrm{HAuCl} 4$ and $10 \mathrm{mM}$ ascorbic acid with 5\% agarose is shown in the plot. 


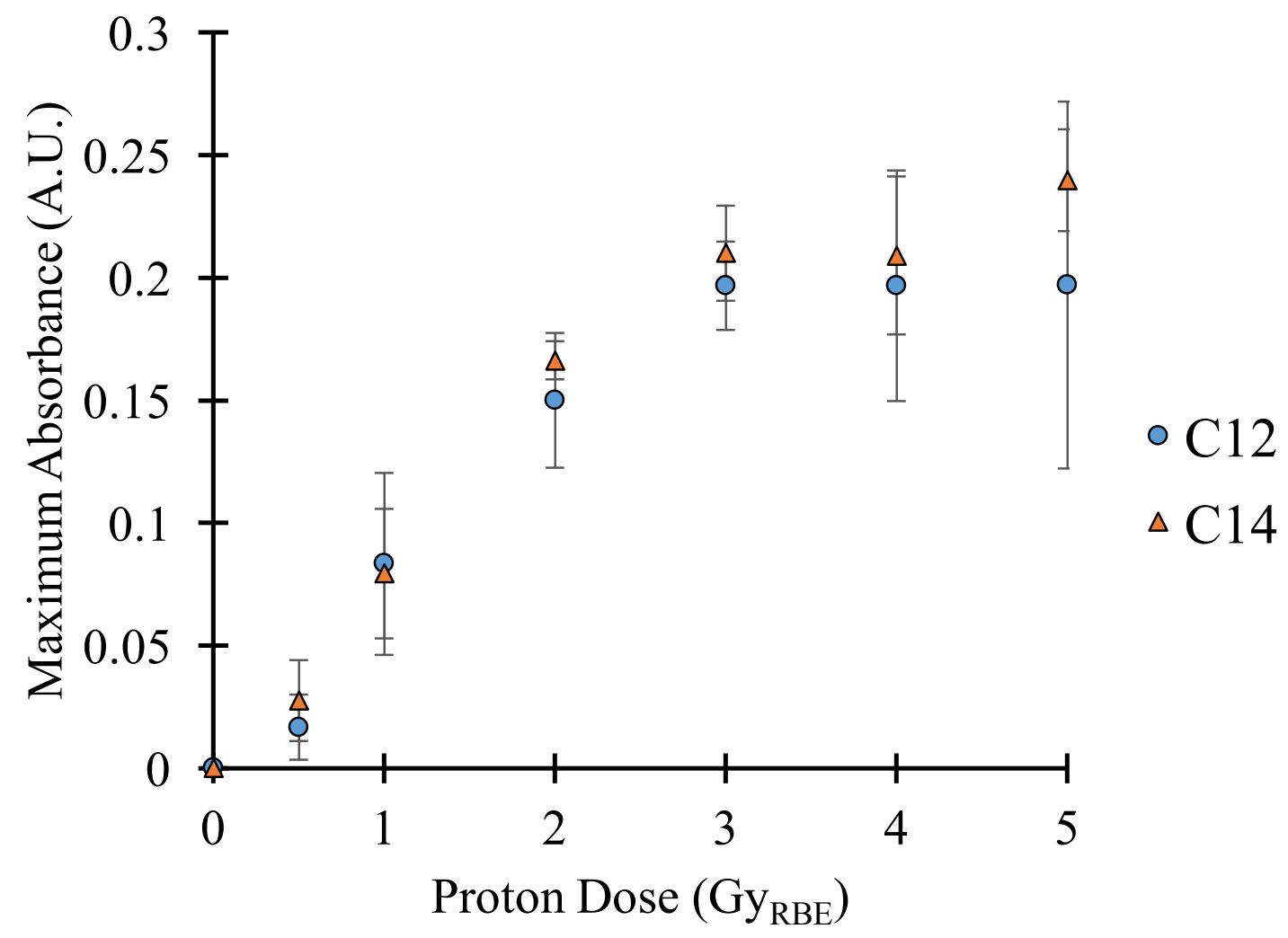

Figure 2.3.10. Absorbance spectra of the nanosensor gel following irradiation with proton beam therapy; A plot depicting maximum absorbance vs radiation dose 2 hrs post irradiation is shown. The formulation of gels with (A) blue circles representing $\mathrm{C}_{12} \mathrm{TAB}$ surfactant while $(\mathbf{B})$ orange triangles representing $\mathrm{C}_{14} \mathrm{TAB}$ with $10 \mathrm{mM} \mathrm{HAuCl}_{4}$ and 10 $\mathrm{mM}$ ascorbic acid with 5\% agarose is shown in the plot.

Reaction volumes on the nanoscale can enhance reaction rates of $\mathrm{e}_{\text {aq }}^{-}$generated upon radiolysis with $\left[\mathrm{AuBr}_{2}\right]^{-}$ions attached to the head group of the micelle. It has been previously reported that the efficiency of charge transfer was enhanced in presence of cationic micelles (hexadecyltrimethylammonium bromide or CTAB micelles and a mixture of CTAB and cetylpyridinium or CP micelles) compared to anionic micelles. ${ }^{29}$ It was hypothesized that the hydrated electrons were more easily transported in the solvent, 
possibly due to the favorable attractive force between this negatively charged species and cationic micelles. ${ }^{30}$ This attractive force can lead to an increased probability of capture of hydrated electrons by the micelle and reaction with $\left[\mathrm{AuBr}_{2}\right]^{-}$. When these electrons interact with an empty site (i.e. no $\mathrm{Au}^{+}$is present), an electron hopping / migration mechanism can facilitate intermicellar reaction between $\mathrm{Au}^{+}$ions and hydrated electrons leading to the formation of $\mathrm{Au}^{0}$ atoms. ${ }^{31}$

Compared to $\mathrm{C}_{10} \mathrm{TAB}$ and $\mathrm{C}_{16} \mathrm{TAB}, \mathrm{C}_{12} \mathrm{TAB}$ and $\mathrm{C}_{14} \mathrm{TAB}$ showed higher efficacies of nanoparticle formation, as indicated by the maximum absorbance determined for a given radiation dose. In absence of micelles, hydrated electrons are not influenced by the positive field and hence recombine and participate in secondary chemical reactions before reacting with $\mathrm{Au}^{+}$ions. This leads to a reduced yield of $\mathrm{Au}^{0}$ atoms which, in turn, results in low yields of gold nanoparticles. In our current formulation, $\mathrm{C}_{10} \mathrm{TAB}$ does not form micelles, and it has a tendency to form a lower yield of nanoparticles under ionizing irradiation compared to $\mathrm{C}_{\mathrm{x}} \mathrm{TAB}(\mathrm{x}=12,14) . \mathrm{C}_{16} \mathrm{TAB}$ has a stronger positive electrostatic field compared to the other surfactants employed in the study due to the higher aggregation number required to form a micelle. ${ }^{32}$ The availability of hydrated electrons for reducing $\mathrm{Au}^{+}$ions is significantly reduced under the influence of a strong electrostatic field. This results in lower yields of zerovalent $\mathrm{Au}^{0}$ ions, which, in turn, is responsible for lower yields of gold nanoparticles. Experimentally, this is captured by the lower absorbance values seen in case of $\mathrm{C}_{16} \mathrm{TAB}$ compared to $\mathrm{C}_{12} \mathrm{TAB}$ or $\mathrm{C}_{14} \mathrm{TAB}$ under similar irradiation conditions. We suggest that $\mathrm{C}_{12} \mathrm{TAB}$ and $\mathrm{C}_{14} \mathrm{TAB}$ form micellar nanostructures with surface charge characteristics that are necessary for facilitating the 
formation of gold nanoparticles in gels in a dose-dependent manner following proton irradiation.

We next evaluated the performance of our nanosensor with $\mathrm{C}_{12} \mathrm{TAB}$ or $\mathrm{C}_{14} \mathrm{TAB}$ formulated in the agarose gel. A linear correlation between gold nanoparticle absorbance and radiation dose was found in the range of $0-3 \mathrm{~Gy}_{\mathrm{RBE}}$ for both $\mathrm{C}_{12} \mathrm{TAB}$ and $\mathrm{C}_{14} \mathrm{TAB}$ (Figure 2.3.11.).

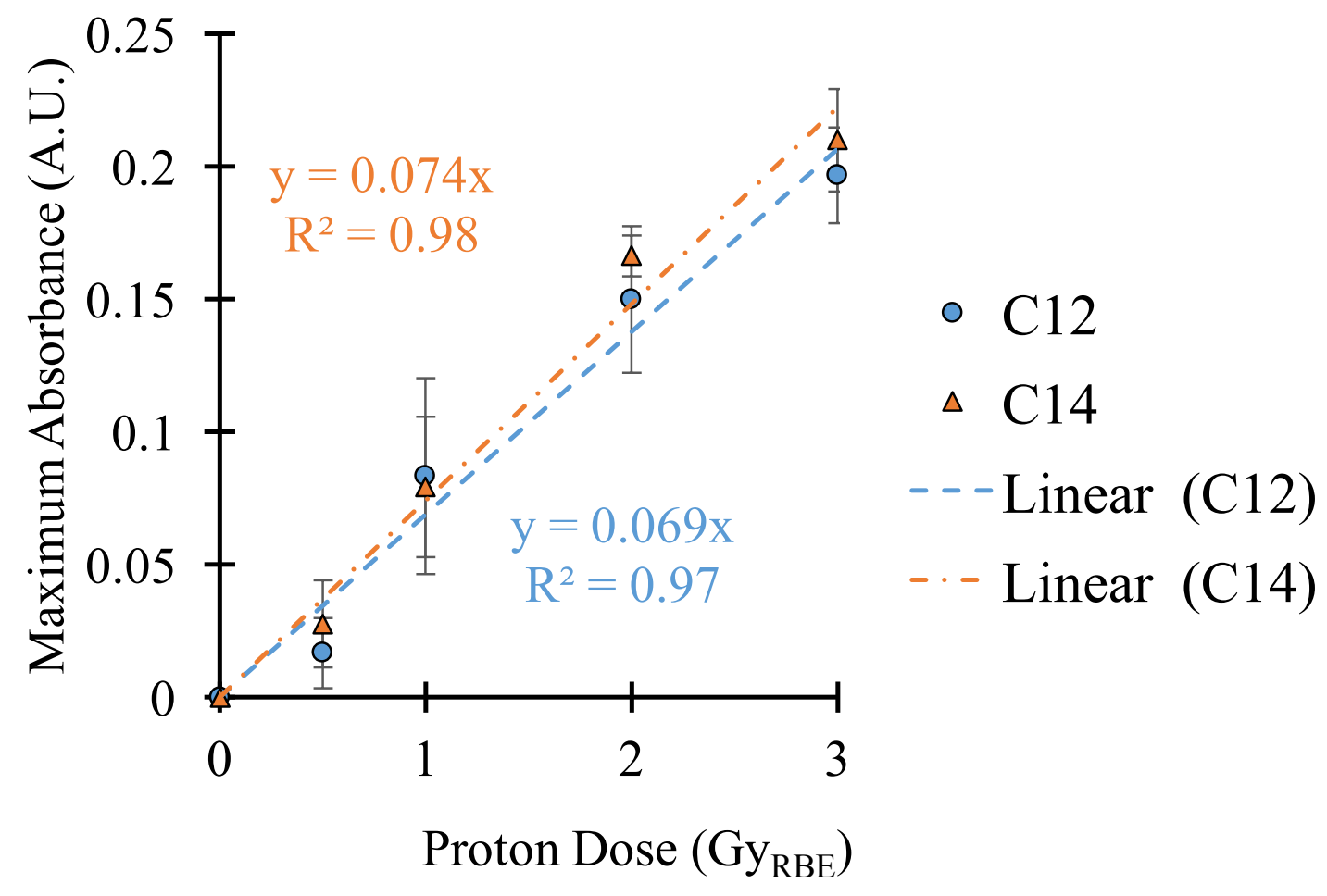

Figure 2.3.11. Calibration curve for $\mathrm{C}_{12} \mathrm{TAB}$ (blue dotted line) and $\mathrm{C}_{14} \mathrm{TAB}$ (orange dotted line) using maximum absorbance vs proton dose from 0 - $3 \mathrm{~Gy}_{\mathrm{RBE}}, 2 \mathrm{~h}$ post irradiation. 
The calibration curve with $\mathrm{C}_{12} \mathrm{TAB}$ had a correlation of $\mathrm{y}=0.069 \mathrm{x}$, while that with $\mathrm{C}_{14} \mathrm{TAB}$ was $\mathrm{y}=0.074 \mathrm{x}$. A test dose of $1.5 \mathrm{~Gy}_{\mathrm{RBE}}$ was delivered to the gel to investigate the predictive ability of these calibrations. The color change of this test gel was quantified 2 hours post irradiation using the resepctive calibrations, which indicated a dose of $1.8 \pm 0.44 \mathrm{~Gy}_{\mathrm{RBE}}$ for the $\mathrm{C}_{12} \mathrm{TAB}$ gels and $2.1 \pm 0.1 \mathrm{~Gy}_{\mathrm{RBE}}$ for the $\mathrm{C}_{14} \mathrm{TAB}$ surfactant gels, indicating better predictive ability of the $\mathrm{C}_{12} \mathrm{TAB}$ gels.

An anthropomorphic child phantom was used to investigate the translational potential of the plasmonic nanosensor hydrogel (Figure 2.3.12). Gels with $\mathrm{C}_{12} \mathrm{TAB}$ or $\mathrm{C}_{14} \mathrm{TAB}$ surfactants were employed in the phantom studies, because of the better calibration curves obtained with these surfactants compared to the others. The gels were placed within the defined field under the spine of the phantom (Figure 2.3.12.) and subjected to a dose of $1.8 \mathrm{~Gy}_{\mathrm{RBE}}$; the respective calibration curves from 0-3 Gy estimation of the dose delivered. 
(A)

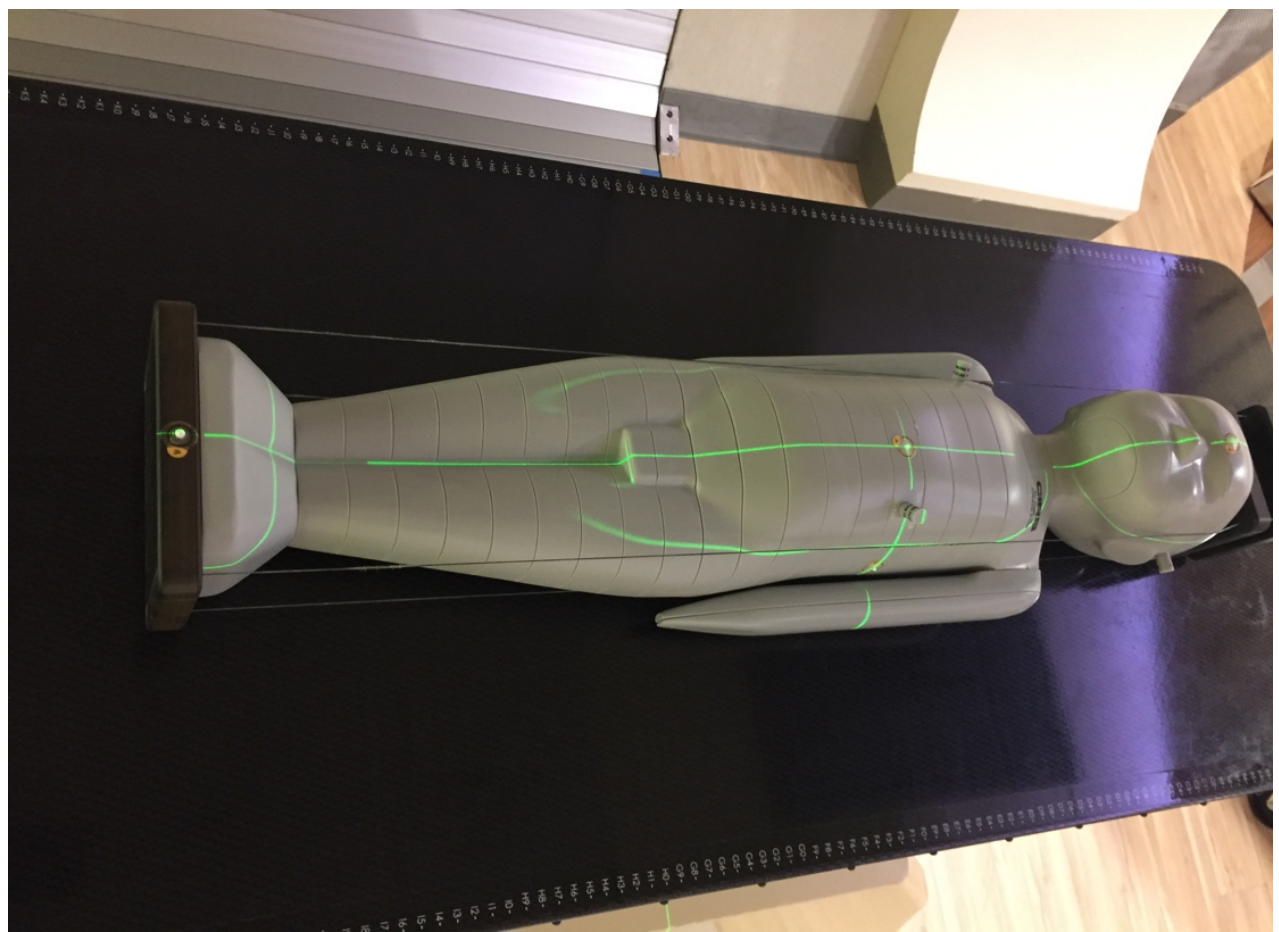

(B) 

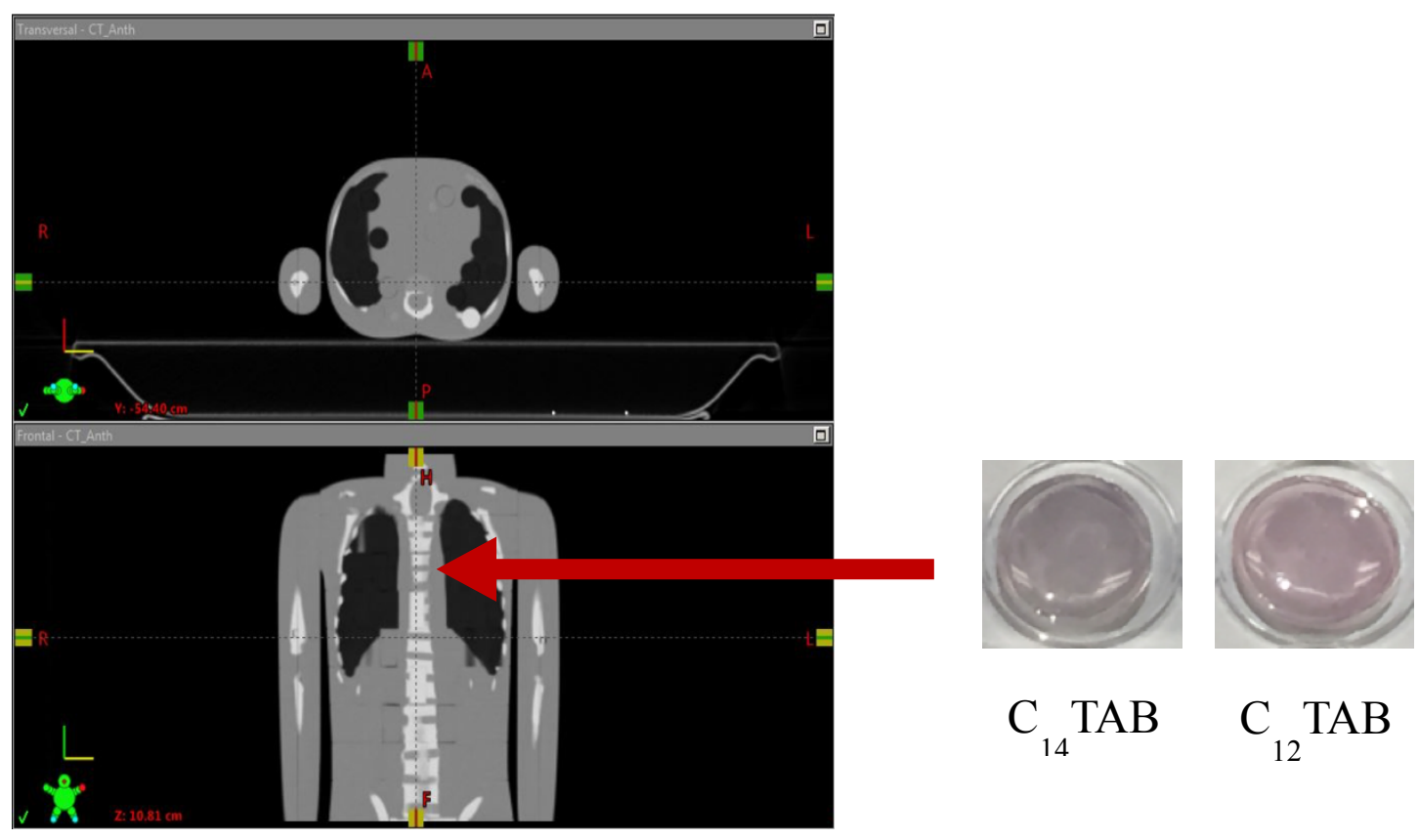

Figure 2.3.12. (A) Evaluation of the predictive ability of hydrogel nanosensors using an anthropomorphic child phantom placed on the irradiation table and subjected to proton therapy. (B) an X-ray computed tomography (CT) scan image of the phantom used in the experiments. The spinal cord of the phantom is irradiated with $1.8 \mathrm{~Gy}_{\mathrm{RBE}}$.

\begin{tabular}{|c|c|c|}
\hline Surfactant & $\begin{array}{c}\text { Actual Dose } \\
\text { Delivered (Gy }\end{array}$ & $\begin{array}{c}\text { Average Dose } \\
\text { Delivered } \pm \\
\text { one S.D. (Gy }\end{array}$ \\
\hline $\left.\mathrm{C}_{12} \mathrm{TAB}\right)$
\end{tabular}

Table 2.3.1. The table indicates the dose delivered to each of the surfactants employed in the experiments and the average dose calculated using the $\mathrm{C}_{12} \mathrm{TAB}$ and $\mathrm{C}_{14} \mathrm{TAB}$-based hydrogel nanosensors. 
A prediction of $1.6 \pm 0.2 \mathrm{~Gy}_{\mathrm{RBE}}$ was made using the calibration curve for $\mathrm{C}_{12} \mathrm{TAB}$, and a prediction of $1.4 \pm 0.4 \mathrm{~Gy}_{\mathrm{RBE}}$ was made using the calibration curve for $\mathrm{C}_{14} \mathrm{TAB}$ calibration curve, respectively (Table 2.3.1.). Our nanosensor hydrogel with $\mathrm{C}_{12} \mathrm{TAB}$ surfactant shows an $11 \%$ error to the true value of the dose delivered (i.e. $1.8 \mathrm{~Gy}_{\mathrm{RBE}}$ ). Clinically used MOSFETs have been found to give an error percentage of $\pm 5 \%$ which is comparable to our current system. ${ }^{33}$ The clearly visible color change, simple detection technique using absorbance spectroscopy, and the ability to quantitatively predict doses demonstrates the potential of the hydrogel nanosensor for dosimetry in fractionated proton beam radiotherapy in the clinic. 


\section{CHAPTER 3}

\section{CONCLUSIONS}

\section{Conclusion}

To our knowledge, we have developed the first gel-based colorimetric nanosensor for detecting and predicting the dose delivered in proton beam therapy. The hydrogel nanosensor was able to detect doses as low as $0.5 \mathrm{~Gy}$ RBE and showed a robust linear range between 0-3 Gy $\mathrm{H}_{\mathrm{RBE}}$. The gel nanosensor was able to predict the dose delivered to an anthropomorphic child phantom with significant accuracy, indicating promise for translation to the clinic. In addition to the simple, visible, stable and quantifiable nature of the readout, the hydrogel system can be contoured for patient personalized treatments. We believe that this one-of-a-kind nanosensor holds high promise for translation to clinical proton beam therapy.

\section{Future Work}

Agarose and ascorbic acid are generally regarded as safe, and $\mathrm{C}_{16} \mathrm{TAB}$ is used in antibacterial formulations used on skin. ${ }^{34}$

- Although the surfactants used in the formulation of the gels can be toxic at elevated concentrations, use of secondary containment devices or eventual replacement of the surfactant with biocompatible templating molecules will alleviate these concerns.

- The development of a new generation of cationic surfactants that allow for precise control of nanoparticle size and yields can lead to sensors with improved prediction abilities. 
- Patterning nanoparticles post irradiation for spatial dose detection.

- Use of the hydrogel dosimeters in endorectal balloons and SpaceOARs. 


\section{REFERENCES}

1. Baumann, M.; Krause, M.; Overgaard, J.; Debus, J.; Bentzen, S. M.; Daartz, J.; Richter, C.; Zips, D.; Bortfeld, T., Radiation oncology in the era of precision medicine. Nat Rev Cancer 2016, 16 (4), 234-249.

2. Ajlouni, M., Radiation-induced proctitis. 2017, 2 (1), 20-26.

3. Branislav Jeremic, Y. S., Biljana Milicic, Nebojsa Nikolic, Aleksandar Dagovic, Jasna Aleksandrovic, Zeljko Vaskovic, Ljiljana Tadic, Hyperfractionated Radiation Therapy With or Without Concurrent Low-Dose Daily Cisplatin in Locally Advanced Squamous Cell Carcinoma of the Head and Neck: A Prospective Randomized Trial. Journal of Clinical Oncology 2000, 18 (7), 1458-1464.

4. Agata Kacprowska, J. J., Hypofractionated radiotherapy for early breast cancer: Review of phase III studies - ScienceDirect. Reports of practical oncology and radiotherapy 2012, 17 (2), 66-70.

5. Daniela Schulz-Ertner, H. T., Particle Radiation Therapy Using Proton and Heavier Ion Beams. http://dx.doi.org/10.1200/JCO.2006.09.7816 2016, 25 (8), 953-964.

6. Olivera, G. H.; Kessler, C.; Sansogne, R. A.; Saraví, M., Energy dependence of the response of thermoluminescence dosimeters to photon and electron beams. Nuclear Instruments and Methods in Physics Research Section B: Beam Interactions with Materials and Atoms 1994, 84 (1), 89-94.

7. Pushpavanam, K.; Narayanan, E.; Rege, K., Molecular and Nanoscale Sensors for Detecting Ionizing Radiation in Radiotherapy. ChemNanoMat 2016, 2 (5), 385-395.

8. Fang-Fang Yin and Mark Oldham and Jing Cai and Qiuwen, W., Dosimetry challenges for implementing emerging technologies. Journal of Physics: Conference Series 2010, 250 (1), 012002.

9. Kneipp, J.; Kneipp, H.; Kneipp, K., SERS - a single-molecule and nanoscale tool for bioanalytics. Chemical Society Reviews 2008, 37 (5), 1052-1060.

10. Karen M. Schaich, M. K., Free radical reactions of peroxidizing lipids with amino acids and proteins: An ESR study | SpringerLink. Lipids 1975, 11 (5), 392-400.

11. Karthik Pushpavanam, E. N., and Kaushal Rege, Molecular and Nanoscale Sensors for Detecting lonizing Radiation in Radiotherapy. ChemNanoMat 2016, 2 (5), 385-395. 
12. Pushpavanam, K.; Narayanan, E.; Chang, J.; Sapareto, S.; Rege, K., A Colorimetric Plasmonic Nanosensor for Dosimetry of Therapeutic Levels of Ionizing Radiation. ACS nano 2015, 9 (12), 11540-11550.

13. Archambeau, J. O.; Bennett, G. W.; Levine, G. S.; Cowen, R.; Akanuma, A., Proton Radiation Therapy. http://dx.doi.org/10.1148/110.2.445 1974, 110 (2), 445-457.

14. Wayne, D. N. a. R. Z., The physics of proton therapy. Physics in Medicine \& Biology 2015, 60 (8), R155.

15. Wilson, R. R., Radiological Use of Fast Protons. Radiology 1946, 47 (5), 487-491.

16. Bethe, H., Zur Theorie des Durchgangs schneller Korpuskularstrahlen durch Materie. Annalen der Physik 1930, 397 (3), 325-400.

17. Oldham, M., Radiation physics and applications in therapeutic medicine IOPscience. Physics Education 2001, 36 (6), 460.

18. Walker, C. R.; Pushpavanam, K.; Nair, D. G.; Potta, T.; Sutiyoso, C.; Kodibagkar, V. D.; Sapareto, S.; Chang, J.; Rege, K., Generation of Polypeptide-Templated Gold Nanoparticles using lonizing Radiation. Langmuir 2013, 29 (32), 10166-10173.

19. Pushpavanam, K.; Inamdar, S.; Chang, J.; Bista, T.; Sapareto, S.; Rege, K., Detection of Therapeutic Levels of Ionizing Radiation Using Plasmonic Nanosensor Gels. Advanced Functional Materials 2017, 27 (21), 1606724-n/a.

20. Pushpavanam, K.; Chang, J.; Sapareto, S.; Rege, K., Polypeptide-facilitated Formation of Bimetallic Plasmonic Nanoparticles in Presence of Ionizing Radiation. Nano LIFE 2017, 07, 1650006.

21. Jana, N. R.; Gearheart, L.; Murphy, C. J., Wet Chemical Synthesis of High Aspect Ratio Cylindrical Gold Nanorods. The Journal of Physical Chemistry B 2001, 105 (19), 4065-4067.

22. Anandhakumar, S.; Rajaram, R.; Mathiyarasu, J., Unusual seedless approach to gold nanoparticle synthesis: application to selective rapid naked eye detection of mercury(ii). Analyst 2014, 139 (13), 3356-3359.

23. Pimblott, S. M.; LaVerne, J. A., Stochastic Simulation of the Electron Radiolysis of Water and Aqueous Solutions. The Journal of Physical Chemistry A 1997, 101 (33), 58285838. 
24. Chitose, N.; Katsumura, Y.; Domae, M.; Cai, Z.; Muroya, Y.; Murakami, T.; LaVerne, J. A., Radiolysis of Aqueous Solutions with Pulsed Ion Beams. 4. Product Yields for Proton Beams in Solutions of Thiocyanate and Methyl Viologen/Formate. The Journal of Physical Chemistry A 2001, 105 (20), 4902-4907.

25. Yen, G.-C.; Duh, P.-D.; Tsai, H.-L., Antioxidant and pro-oxidant properties of ascorbic acid and gallic acid. Food Chemistry 2002, 79 (3), 307-313.

26. Khan, Z.; Singh, T.; Hussain, J. I.; Hashmi, A. A., Au(III)-CTAB reduction by ascorbic acid: Preparation and characterization of gold nanoparticles. Colloids and Surfaces B: Biointerfaces 2013, 104 (0), 11-17.

27. Wen, X.-L.; Liu, Z.-L.; Han, Z.-X.; Rieker, A., Significant Micellar Effect on the Oxidative Electrochemistry of Ascorbic Acid[dagger]. Journal of Chemical Research, Synopses 1997, (3), 108-109.

28. Akisada, H.; Kuwahara, J.; Koga, A.; Motoyama, H.; Kaneda, H., Unusual behavior of CMC for binary mixtures of alkyltrimethylammonium bromides: Dependence on chain length difference. Journal of Colloid and Interface Science 2007, 315 (2), 678-684.

29. Patterson, L. K.; Graetzel, M., Behavior of hydrated electrons in micellar solution. Cetyltrimethylammonium bromide-cetylpyridinium chloride mixed micelles. The Journal of Physical Chemistry 1975, 79 (10), 956-960.

30. Thanacharoenchumrut, S.; Angboonpong, N.; Pakawatpanurut, P., Cationic cetylpyridinium micelle as a novel electrolyte system for dye-sensitized solar cells. Journal of Power Sources 2016, 307, 443-448.

31. Szajdzinska-Pietek, E.; Gebicki, J. L.; Kroh, J., Pulse Radiolytic Investigation on Intermicellar Transport of Hydrated Electron in Cationic Micellar Solutions of Alkyltrimethylammonium Halides. Journal of Colloid and Interface Science 1995, 176 (1), 264-266.

32. Kuznetsov, V. S.; Usol'tseva, N. V.; Bykova, V. V., Electrostatic interactions in micellar solutions of sodium n-alkyl sulfates and applicability of the poissonboltzmann equation for their calculation. Journal of Structural Chemistry 2012, 53 (1), 82-92.

33. Kohno, R.; Hotta, K.; Matsubara, K.; Nishioka, S.; Matsuura, T.; Kawashima, M., In vivo proton dosimetry using a MOSFET detector in an anthropomorphic phantom with tissue inhomogeneity. Journal of Applied Clinical Medical Physics 2012, 13 (2), 159-167. 
34. Nakata, K.; Tsuchido, T.; Matsumura, Y., Antimicrobial cationic surfactant, cetyltrimethylammonium bromide, induces superoxide stress in Escherichia coli cells. Journal of Applied Microbiology 2011, 110 (2), 568-579. 